Research Article

\title{
Mix Design of Recycled Coarse Aggregate Self-Compacting Concrete Based on Orthogonal Test and Analysis of Mercury Intrusion Porosimetry
}

\author{
Songpu Gao (D), Qing Liu (iD, Fengxia Han $(D$, and Yu Fu (iD \\ College of Architectural and Civil Engineering, Xinjiang University, Urumqi 830047, China \\ Correspondence should be addressed to Qing Liu; liuqing2666@163.com
}

Received 14 April 2021; Revised 9 June 2021; Accepted 16 June 2021; Published 2 July 2021

Academic Editor: Zbyšek Pavlík

Copyright (C) 2021 Songpu Gao et al. This is an open access article distributed under the Creative Commons Attribution License, which permits unrestricted use, distribution, and reproduction in any medium, provided the original work is properly cited.

\begin{abstract}
The influence of four factors (water-binder ratio, recycled coarse aggregate replacement rate, fly ash substitution rate, and superplasticizer content) on the workabilities and mechanical properties of recycled coarse aggregate self-compacting concrete (RCASCC) was studied using the orthogonal test method. Based on the orthogonal test design and range analysis method of the fresh and hardened properties of RCASCC, the optimal mix is as follows: water-binder ratio of 0.269 , recycled coarse aggregate replacement rate of $30 \%$, fly ash substitution rate of $40 \%$, and superplasticizer content of $0.50 \%$. Then, the porosity and aperture size distribution of nine groups of RCASCC were tested by mercury intrusion porosimetry (MIP) at the microlevel. The macroscopic and microscopic relationship was established by combining the results of mechanical property tests and MIP. Fractal dimension $D$ of the B.B. Mandelbrot model was used to study the fractal characteristics of pore volume of RCASCC. Results showed that porosity and strengths are negatively correlated, and the relative strength can be roughly judged according to the porosity. The pore structure of nine groups of RCASCC materials has evident fractal characteristics of irregular shape. The complex pore structure adversely affects strength.
\end{abstract}

\section{Introduction}

Concrete is one of the most versatile building materials on Earth and makes up a significant proportion of the past, present, and future infrastructure [1]. Since the application of concrete materials in the middle of the 19th century, it has developed from ordinary concrete to high-strength concrete, high-performance concrete, and green high-strength concrete finally. As a high-performance concrete, self-compacting concrete (SCC) has been widely used in many countries and regions in the world, such as Japan, the United States, and Europe, because it does not require vibrating during pouring and has the advantages of high fluidity, uniformity, and stability $[2,3]$. SCC requires higher powder and chemical admixture content than traditional concrete so that its cost is higher [4]. The method of mixing and disposing fly ash and steel slag has been adopted to reduce costs. Another cost-effective and environmentally friendly method to produce SCC might be the utilization of recycled concrete aggregate (RCA).

The recycled concrete technology can effectively alleviate the ecological crisis caused by the excessive use of natural stones and can reduce the environmental pollution caused by construction waste. Recycling demolished waste concrete as coarse aggregate has become an international consensus nowadays [5]. In this context, the use of RCA in the preparation of SCC can not only save resources and protect the environment but also improve the construction conditions of concrete projects, save construction costs, and further maximize the use of construction wastes [6]. However, previous studies found that recycled aggregate often has some defects, such as higher water absorption and weaker interface transition zone connection, thereby resulting in poor mechanical properties of concrete prepared [7-9]. Therefore, in the configuration process of recycled concrete, the mix was often different, leading to different workabilities and mechanical 
properties of concrete. González-Taboada et al. [10] conducted tests on SCC with different replacement rates of RCA, and they found that most performance parameters were negatively affected by the increase in the replacement rates of recycled aggregate. However, Pereira-de-Oliveira et al. [11] demonstrated that recycled aggregates do not significantly influence the mechanical behavior of SCC. They found a very low difference of 5\% between SCC and SCC with 100\% replacement ratio. Güneyisi et al. [12] explored the treatment methods of recycled aggregates. Microstructure consequences from SEM analysis showed that the interfacial zone between new cement paste and treated RCA exhibits less pore characteristics, which are significantly different compared with those of SCC with untreated RCA. Most aggregate treatment methods have improved the workabilities and mechanical properties of SCC.

Generally speaking, mix design is the first importance for concrete production. Mix design and the properties of fresh concrete are the most critical points in relation to the mechanical characteristics of hardened SCC [13]. At present, the research literature for SCC mix design is based on the experience of Japan [14, 15], France [16], and Sweden [17]. The existing methods for formulating SCC are mainly based on empirical. The orthogonal test method belongs to one of the empirical parameter-based design methods, which was first proposed by Japanese statistician Genichi Taguchi [18]. Taguchi experimental design is a test method that uses orthogonal tables to select experimental conditions and arrange experiments. The orthogonal test method is characterized by balanced dispersion and comprehensive comparability, and it is a scientific method to study and deal with the multifactor test. The results of concrete mix test according to this method can objectively reflect the configuration regularity, and it is convenient to optimize the mix ratio. The idea is that studying the total amount of cementitious materials, sand ratio, water-cement ratio, admixture, and other different factors for the concrete work performance and strength to determine the reasonable dosage range of each parameter. Then, according to the ordinary concrete mix design method for the calculation, the orthogonal test method is adopted to improve the concrete mixture ratio test [19-21]. Several authors have demonstrated the applicability of the orthogonal test method for the SCC and recycled aggregate concrete (RAC). However, few about RCASCC because there are more than ten preparation methods of SCC, for different kinds of coarse and fine aggregates for its replacement made of RCASCC preparation methods are innumerable. Prasad et al. [22] adopted the Taguchi method for optimal design of experiments. The results showed that concrete designed in $\mathrm{L}_{9}$ orthogonal array with $25 \%$ replacement of cement with fly ash, $20 \%$ replacement of fine aggregate with waste foundry sand, and addition of $1 \%$ polypropylene fibers was found to be the optimal mix for maximum compressive strength and split tensile strength. Mohammed and Najim [23] used an orthogonal test method to demonstrate that the compressive strength and flexural strength of RCASCC decreased with the increase in replacement rate of recycled aggregate, but they could reach the expected strength. Ozbay et al. [24] mix proportion parameters of high-strength self-compacting concrete (HSSCC) are analyzed by using Taguchi's experiment design methodology for optimal design. In the results of fresh and hardened concrete properties of produced concrete samples, they satisfied the expected properties of HSSCC.

According to previous studies, designing the mix and analyzing the basic mechanical properties of RCASCC are very important, but the analysis of the mix and macroscopic mechanical properties from the microperspective combined with the fractal theory is very rare. Not many studies have applied the orthogonal test method to the configuration of RCASCC. This article initially uses the method of orthogonal experiment to analyze the mix from the perspectives of macro workabilities and mechanical properties and then through microscopic analysis of MIP and combined with the fractal dimension model to establish the aperture size distribution, porosity, mechanical properties, fractal dimension, and relationships. Finally, strength tests are conducted to obtain an accurate optimal mix to prove the accuracy and applicability of mix, which can provide reference for the design and application of RCASCC in green concrete projects.

\section{Materials and Methods}

2.1. Material Properties. P.O42.5 ordinary Portland cement was used in this test, and the basic physical properties are shown in Table 1 . The natural fine aggregate is a continuous grading natural sand of $160 \mu \mathrm{m}$ to $5 \mathrm{~mm}$ particle size, with a fineness modulus of 3.6 and an apparent density of $2670 \mathrm{~kg} /$ $\mathrm{m}^{3}$. The grade of fly ash is II, and the physical properties are shown in Table 2. RCA came from the real demolition debris of the Bahuliang residential building in Tianshan District, Urumqi, Xinjiang. The demolition buildings were self-built buildings, which have been in service for about 30 years. The main structure of the buildings was reinforced concrete frame structure. According to the previous research of Liu [25], the aggregates from Xinjiang had different shape and properties from other areas in China. Most RCAs are composed of natural pebbles and mortar with different proportions on the surface. Few RCAs are made up of cement mortar or natural pebbles, but the proportion is relatively small. The surface of RCA is concave-convex, with bubbles and cracks coexisting, as shown in Figure 1. Table 3 and 4 show some properties of coarse aggregate. The test method for crushing index, coarse aggregate particle size, and gradation are in accordance with the current standard "Recycled Coarse Aggregate for Concrete" (GB/T251772010) [26] and "Standard for Quality and Inspection Method 
TABLE 1: Basic properties of cement.

\begin{tabular}{|c|c|c|c|c|c|c|}
\hline \multirow[t]{2}{*}{ Cement stability } & \multirow[t]{2}{*}{ Fineness (sieve size: $80 \mu \mathrm{m}$ )/\% } & \multirow[t]{2}{*}{ Specific surface $\left(\mathrm{m}^{2} / \mathrm{kg}\right)$} & \multicolumn{2}{|c|}{ Setting time (s) } & \multicolumn{2}{|c|}{$\begin{array}{c}\text { Compressive } \\
\text { strength } \\
(\mathrm{MPa})\end{array}$} \\
\hline & & & Initial & Final & $3 \mathrm{~d}$ & $28 \mathrm{~d}$ \\
\hline Qualified & 0.6 & 380 & 150 & 210 & 29 & 49 \\
\hline
\end{tabular}

TABLe 2: Physical properties of fly ash.

\begin{tabular}{lccc}
\hline Fineness (\%) & Ignition loss (\%) & Water absorption (\%) & Apparent density $\left(\mathrm{kg} / \mathrm{m}^{3}\right)$ \\
\hline 29 & 2.8 & 98 & 2050 \\
\hline
\end{tabular}

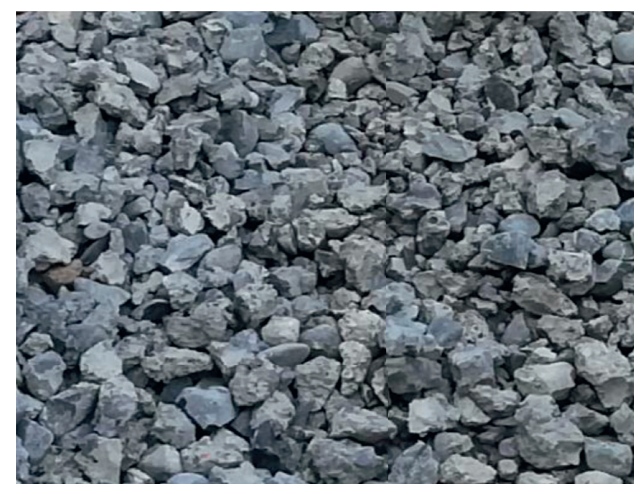

(a)
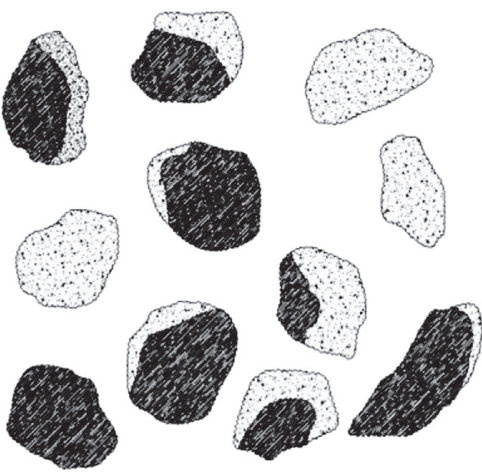

(b)

Figure 1: Schematic diagram of RCA. (a) RCA after treatment. (b) Shape of RCA used.

TABLE 3: Aggregate properties.

\begin{tabular}{lcccc}
\hline Aggregate category & Gradation $(\mathrm{mm})$ & Apparent density $\left(\mathrm{kg} / \mathrm{m}^{3}\right)$ & Mean crushing index $(\%)$ & Mean water absorption $(\%)$ \\
\hline NCA & $5-20$ & 2650 & 3.88 & 4.01 \\
RCA & $5-20$ & 2535 & 13.93 & 6.85 \\
\hline
\end{tabular}

Note. NCA: natural coarse aggregate; RAC: recycled coarse aggregate.

TABLE 4: Recycled coarse aggregate gradation.

\begin{tabular}{lccc}
\hline Particle size $(\mathrm{mm})$ & Divided sieve residue $(\mathrm{g})$ & Cumulative sieve residue $(\mathrm{g})$ & Cumulative sieve residue percentage $(\%)$ \\
\hline 20.0 & 278 & 278 & 5.60 \\
16.0 & 630 & 908 & 18.27 \\
10.0 & 2221 & 3129 & 62.97 \\
5.0 & 1501 & 4630 & 93.18 \\
2.5 & 339 & 4969 & 100 \\
\hline
\end{tabular}

of Sand and Stone for Common Concrete" (JGJ52-2006) [27]. Polycarboxylate superplasticizer was used for all tested concretes, the state of which is yellow liquid, and the solid content is $37 \%$.

\subsection{Mix Design of SCC}

2.2.1. Trial Mix Design. The trial mix design should be carried out prior to the orthogonal mix design to ensure that the strength of RCASCC can satisfy the requirements of the specification. In this test, the absolute volume method was used to design the mix according to the requirements of
"Technical Specification for Application of Self-Compacting Concrete" (JGJ/T283-2012) [16]. The design strength of concrete in this test is required to reach $50 \mathrm{MPa}$, and the workability of concrete should also satisfy the requirements of secondary SCC. Seven groups of mixture were designed for trial mix, and these groups were named SP1-SP7 groups. The trial mixes and the test results are shown in Tables 5 and 6.

Tables 5 and 6 indicate that the workabilities and mechanical properties of the SP-1 and SP-3 groups were excellent. The mix of SP-1 and SP-3 was fine-tuned to obtain SP-6 and SP-7. Then, the trial mix was carried out. The workability and mechanical property test results showed that 
TABle 5: Trial mix design.

\begin{tabular}{lcccccccc}
\hline Group no. & Water $(\mathrm{kg})$ & Cement $(\mathrm{kg})$ & Fly ash $(\mathrm{kg})$ & Sand $(\mathrm{kg})$ & Stone $(\mathrm{kg})$ & RCA $(\mathrm{kg})$ & Superplasticizer $(\mathrm{g})$ & Additional water $(\mathrm{g})$ \\
\hline SP-1 & 6.48 & 17.85 & 6.69 & 25.47 & 13.90 & 13.90 & 112.8 & 94 \\
SP-2 & 6.48 & 17.85 & 6.24 & 25.95 & 13.73 & 13.73 & 110.8 & 93 \\
SP-3 & 6.48 & 15.61 & 8.03 & 26.43 & 13.50 & 13.50 & 108.7 & 91.8 \\
SP-4 & 6.48 & 16.73 & 7.25 & 25.47 & 13.95 & 13.95 & 110.3 & 94.9 \\
SP-5 & 6.48 & 17.85 & 5.36 & 25.47 & 13.95 & 13.95 & 106.8 & 94.9 \\
SP-6 & 6.48 & 17.18 & 7.36 & 25.47 & 13.90 & 13.90 & 117.8 & 94.5 \\
SP-7 & 6.48 & 15.61 & 8.03 & 26.43 & 13.50 & 13.50 & 122.9 & 91.8 \\
\hline
\end{tabular}

Table 6: Results of trial mix design.

\begin{tabular}{lcccc}
\hline Group no. & $f_{c u, 7 d}(\mathrm{MPa})$ & Slump flow $(\mathrm{mm})$ & V-funnel flow time $(\mathrm{s})$ & $T_{500}(\mathrm{~s})$ \\
\hline SP-1 & 48.6 & 550 & 22 & 5.7 \\
SP-2 & 47.2 & 560 & 20 & 5.5 \\
SP-3 & 52.8 & 700 & 18 & 16.1 \\
SP-4 & 34.4 & 730 & 5 & 3.7 \\
SP-5 & 31.6 & 700 & 32 & 3.1 \\
SP-6 & 49.8 & 680 & 20 & 6.0 \\
SP-7 & 48.6 & 700 & 13 & 4.5 \\
\hline
\end{tabular}

Note. SP: trial mix; $f_{c u}$ : compressive strength.

the properties of SP-6 and SP-7 were excellent. Thus, the SP6 and SP-7 tests were considered the benchmark to carry out the orthogonal design of the mix.

2.2.2. Orthogonal Experimental Design. Orthogonal experimental design refers to a design method that studies multiple factors and levels. It is used to design the experiment by creating a standard orthogonal array in order to taking into account the effect of a number of factors on the target value in addition presenting the experiment plan. This allows collecting the necessary data to determine which factor affects the experiment more than others with a minimum amount of experiments to reduce the required time and resources [23]. By applying the orthogonal experimental design to the preparation of RCASCC, the optimal mix can be obtained conveniently by scientific calculation. Using orthogonal tables to arrange experiments can also avoid blind tests, significantly reduce the number of tests, and shorten the development time. This creates standard Taguchi orthogonal array which is a special standard experimental design that requires a small number of experimental trials to find the main factor that affects the output. To consider the four parameters (waterbinder ratio, recycled coarse aggregate replacement rate, fly ash substitution rate, and superplasticizer content) and three levels correspond to each factor, 81 experiments are required. However, Taguchi approach suggests $\mathrm{L}_{9}$ orthogonal array based on Minitab that was used in this study. In other words, only 9 instead of 81 experiments are required to sufficiently consider and optimize these parameters. Through this trial mix design, the orthogonal table is adopted to design the mix of RCASCC. The specific orthogonal test distribution and material consumption are shown in Tables 7 and 8.

\subsection{Test and Analysis Methods}

2.3.1. Workability Tests. The SCC of the test is class II. Based on "Technical Specification for Application of Self-Compacting Concrete" (CECS 203: 2006) [28] and (JGJ/T2832012) [29], filling ability is a mandatory index for SCC, and passing ability and segregation resistance can be selected according to the structural characteristics and construction requirements of the structure. Combining the actual situation with the planned working condition requirements, we choose indicators of slump flow, slump flow time $\left(T_{500}\right)$, $\mathrm{V}$-funnel flow time, and segregation resistance to test the filling ability and segregation resistance.

2.3.2. Mechanical Property Tests. The mechanical property tests carried out include the following: cube compressive strength test, splitting tensile strength test, prism axial compressive test, and modulus of elasticity. According to the "Standard Test Method for Physical and Mechanical Properties of Concrete" (GB/T50081-2019) [30], the cube size is $150 \mathrm{~mm} \times 150 \mathrm{~mm} \times 150 \mathrm{~mm}$ and the prism size is $150 \mathrm{~mm} \times 150 \mathrm{~mm} \times 300 \mathrm{~mm}$. Modulus of elasticity was determined by the modulus of elasticity test under static compression. We conducted the elastic modulus test for $150 \mathrm{~mm} \times 150 \mathrm{~mm} \times 300 \mathrm{~mm}$ specimens, three specimens were selected for each mix, and the arithmetic mean of the measured values of three specimens was taken as the elastic modulus of the group of specimens. Specimens are shown in Figure 2.

2.3.3. MIP. MIP was used to measure the pore structure parameters of RCASCC. After curing of concretes, a small piece of concrete with a volume of approximately $10 \mathrm{~mm} \times 10 \mathrm{~mm} \times 10 \mathrm{~mm}$ without aggregate was obtained 
TABLE 7: Orthogonal test table.

\begin{tabular}{lcccc}
\hline Mix series & \multicolumn{3}{c}{ Factors } \\
F/B & RCA (\%) & Fly ash (\%) & Superplasticizer (\%) \\
\hline 1. $\mathrm{A}_{1} \mathrm{~B}_{1} \mathrm{C}_{1} \mathrm{D}_{1}$ & 0.264 & 30 & 20 & 0.48 \\
2. $\mathrm{A}_{1} \mathrm{~B}_{2} \mathrm{C}_{2} \mathrm{D}_{2}$ & 0.264 & 40 & 30 & 0.50 \\
3. $\mathrm{A}_{1} \mathrm{~B}_{3} \mathrm{C}_{3} \mathrm{D}_{3}$ & 0.264 & 50 & 40 & 0.52 \\
4. $\mathrm{A}_{2} \mathrm{~B}_{1} \mathrm{C}_{2} \mathrm{D}_{3}$ & 0.269 & 30 & 30 & 0.52 \\
5. $\mathrm{A}_{2} \mathrm{~B}_{2} \mathrm{C}_{3} \mathrm{D}_{1}$ & 0.269 & 40 & 40 & 0.48 \\
6. $\mathrm{A}_{2} \mathrm{~B}_{3} \mathrm{C}_{1} \mathrm{D}_{2}$ & 0.269 & 50 & 20 & 0.50 \\
7. $\mathrm{A}_{3} \mathrm{~B}_{1} \mathrm{C}_{3} \mathrm{D}_{2}$ & 0.274 & 30 & 40 & 0.50 \\
8. $\mathrm{A}_{3} \mathrm{~B}_{2} \mathrm{C}_{1} \mathrm{D}_{3}$ & 0.274 & 40 & 20 & 0.52 \\
9. $\mathrm{A}_{3} \mathrm{~B}_{3} \mathrm{C}_{2} \mathrm{D}_{1}$ & 0.274 & 50 & 30 & 0.48 \\
\hline
\end{tabular}

Note: W/B: water-binder ratio.

TABLE 8: Orthogonal test mix design and material dosage of each group.

\begin{tabular}{|c|c|c|c|c|c|c|c|c|}
\hline \multirow{2}{*}{ Mix series } & \multicolumn{8}{|c|}{$1 \mathrm{~m}^{3}$ RCASCC material consumption $(\mathrm{kg})$} \\
\hline & $\mathrm{W} / \mathrm{B}$ & Water & Cement & Fly ash & Sand & Stone & RCA & Superplasticizer \\
\hline 1. $\mathrm{A}_{1} \mathrm{~B}_{1} \mathrm{C}_{1} \mathrm{D}_{1}$ & 0.264 & 180 & 495.8 & 185.1 & 720.9 & 533.8 & 228.8 & 3.27 \\
\hline 2. $\mathrm{A}_{1} \mathrm{~B}_{2} \mathrm{C}_{2} \mathrm{D}_{2}$ & 0.264 & 180 & 428.3 & 251.6 & 720.9 & 457.5 & 305.0 & 3.40 \\
\hline 3. $\mathrm{A}_{1} \mathrm{~B}_{3} \mathrm{C}_{3} \mathrm{D}_{3}$ & 0.264 & 180 & 360.4 & 319.5 & 720.9 & 381.3 & 381.3 & 3.54 \\
\hline 4. $\mathrm{A}_{2} \mathrm{~B}_{1} \mathrm{C}_{2} \mathrm{D}_{3}$ & 0.269 & 180 & 431.1 & 238.3 & 720.9 & 533.8 & 228.8 & 3.48 \\
\hline 5. $\mathrm{A}_{2} \mathrm{~B}_{2} \mathrm{C}_{3} \mathrm{D}_{1}$ & 0.269 & 180 & 362.1 & 307.2 & 720.9 & 457.5 & 305.0 & 3.21 \\
\hline 6. $\mathrm{A}_{2} \mathrm{~B}_{3} \mathrm{C}_{1} \mathrm{D}_{2}$ & 0.269 & 180 & 495.8 & 173.5 & 720.9 & 381.3 & 381.3 & 3.34 \\
\hline 7. $\mathrm{A}_{3} \mathrm{~B}_{1} \mathrm{C}_{3} \mathrm{D}_{2}$ & 0.274 & 180 & 394.2 & 289.1 & 720.9 & 381.3 & 228.8 & 3.41 \\
\hline 8. $\mathrm{A}_{3} \mathrm{~B}_{2} \mathrm{C}_{1} \mathrm{D}_{3}$ & 0.274 & 180 & 525.6 & 157.7 & 720.9 & 457.5 & 305.0 & 3.55 \\
\hline 9. $\mathrm{A}_{3} \mathrm{~B}_{3} \mathrm{C}_{2} \mathrm{D}_{1}$ & 0.274 & 180 & 433.9 & 223.2 & 720.9 & 533.8 & 381.3 & 3.15 \\
\hline
\end{tabular}

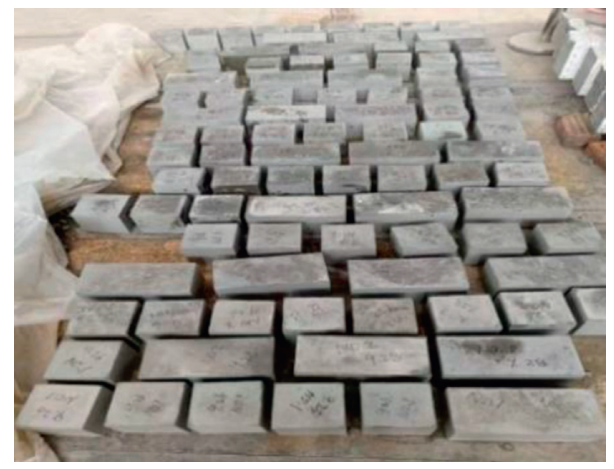

Figure 2: RCASCC.

from the center of the specimen and placed in a dryer at $105^{\circ} \mathrm{C}$ to dry to a constant weight, as shown in Figure 3. Then, it was processed into small pieces in the AutoPore V 9600 high-performance automatic mercury intrusion porosimetry apparatus. The equipment details are shown in Figure 4 . The pressure value and the liquid mercury consumption volume can be calculated by the Washburn formula to obtain the volume of the internal hole of the tested object. The specific expression is as follows:

$$
\Delta p=\frac{2 \gamma \cos \theta}{R}
$$

where $R$ is the apparent pore radius, $\gamma$ is the surface tension of the mercury (usually $485 \times 10^{-3} \mathrm{~N} / \mathrm{m}$ ), $\theta$ is the contact angle between the mercury and the pore surface, and $\Delta p$ is the pressure required to cause the mercury intrusion (it is adequate to attain a contact angle between $130^{\circ}$ and $140^{\circ}$ ).
2.3.4. Range Analysis Method. The range analysis method is commonly used in orthogonal design. Under the condition of small experimental error, we can judge the optimal results of the experiment: the primary and secondary factors, the optimal level, the optimal collocation, and the optimal combination through simple calculation. In the process of obtaining the optimal mix of RCASCC, the range method was adopted for the analysis of workabilities and mechanical properties. The specific formula is as follows:

$$
K_{i}^{p}=\sum_{i=1}^{n} x_{i},
$$

where $p$ is the factor and $i$ is the indicator value of the test results at level $i$ under the corresponding influence factors $(i=1,2,3) . N$ is the number of tests conducted for corresponding influence factors: 


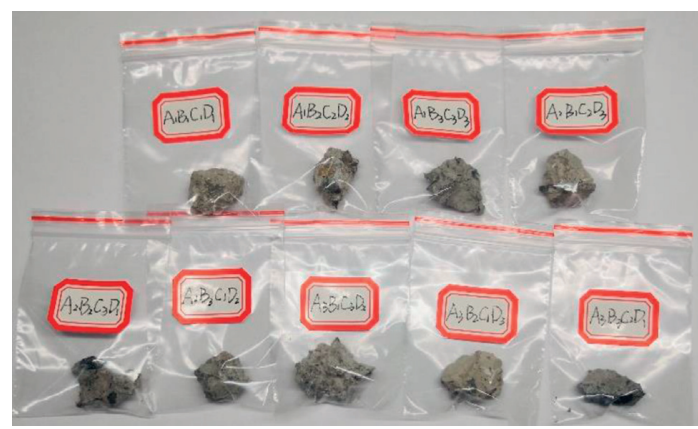

FIgURE 3: Nine groups of RCASCC were sampled for MIP.

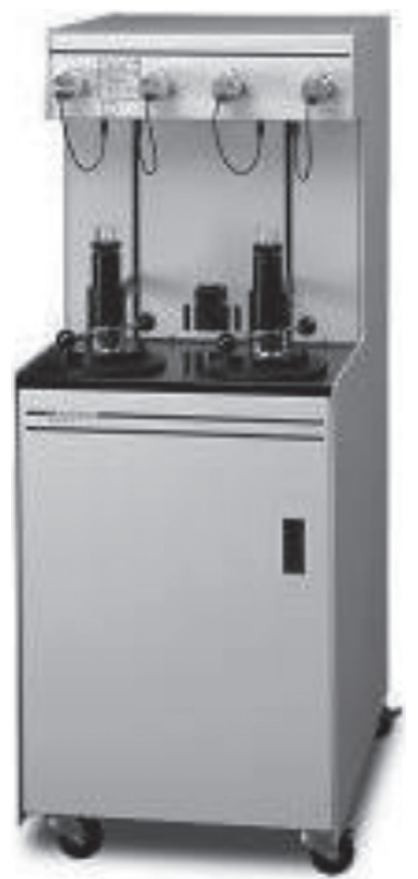

Figure 4: AutoPore V 9600 MIP apparatus.

$$
\begin{aligned}
\bar{K} & =\frac{\sum_{i=1}^{n} K_{i}}{n}, \\
R & =\operatorname{Max} \bar{K}_{i}-\operatorname{Min} \bar{K}_{i},
\end{aligned}
$$

where $K_{i}$ is the combination of test indicators under a certain influence factor. $R$ represents range. The larger the range, the greater the influence of the change of this factor on the test, and the more important this factor is in the test. Otherwise, the less important it is.

2.3.5. Fractal Theory. Fractal geometry originated from the famous French mathematician Mandelbrot [31], it was founded on the basis of studying typical complex natural forms, such as coast line structure, moon surface, and galactic star distribution. Summarizing previous pure mathematical theoretical research in the field of fractal. The research object is irregular with noncharacteristic length shape that is difficult to describe in Euclidean geometry, and it is used to describe irregular phenomena in nature. For most complex natural morphology, statistical self-similarity is observed; that is, the local amplification has the same statistical distribution law in general. $X$ is composed of $N$ similar figures, which are reduced by $X$ times. In formula $N(\varepsilon)=\varepsilon^{D}, D$ has dimensional definition. The general fractal dimension $D$ can be described by the following formula:

$$
D=\frac{\lg N(\varepsilon)}{\lg \varepsilon} .
$$

In the fractal theory, porous concrete materials have fractal characteristics. The distribution of aperture size $r$ of concrete with different sizes indicates that the fractal dimension of pore volume can represent the complexity of pore volume space of concrete. The relationship among any pore size $r$, maximum pore size $r_{\max }$, and pore number $n$ is as follows [32]:

$$
n=\int_{r}^{r_{\max }} \mathrm{Q}(r) \mathrm{d} r=t r^{-D},
$$

where $r_{\max }$ is the largest aperture, the unit of which is nm, $Q(r)$ is the density function, $D$ is the fractal dimension of concrete pores, and $t$ is a constant.

Derivation of both sides of equation (5) is obtained as follows:

$$
\frac{\mathrm{d} n}{\mathrm{~d} r}=Q(r)=t_{1} r^{-D-1},
$$

where $t_{1}$ is a constant, and the cumulative pore volume of less than $r$ in concrete pores is as follows:

$$
V=\int_{r_{\min }}^{r} Q(r) t r^{3} \mathrm{~d} r .
$$

In the formula, $t$ is related to the pore shape. When the volume of concrete is a spherical hole, $t=4 \pi / 3, r_{\min }$ is the minimum pore diameter. Combined with the above formula, we can obtain the following:

$$
V(<r)=t_{3}\left(r^{3-D}-r_{\min }^{D}\right)
$$

where $t_{3}$ is a constant:

$$
V_{G}=V\left(r_{\min }\right)=t_{3}\left(r^{3-D}-r_{\min }^{3-D}\right) .
$$

In the formula, because $r_{\max }$ is much larger than $r_{\min }$, the value of $r_{\text {min }}$ is ignored. The pore volume fraction $u$ is obtained as follows:

$$
u=\frac{V(r)}{V_{G}}=\frac{r^{3-D}}{r_{\max }^{3-D}} .
$$

The logarithm of both sides of the equation is obtained to compute the following:

$$
\log u=(3-D)\left(\log \frac{r}{r_{\max }}\right) .
$$

Set 


$$
\begin{aligned}
& \log u=y, \\
& \frac{\log r}{r_{\max }}=x .
\end{aligned}
$$

The fractal dimension $D$ of the pore volume of RCASCC based on aperture size distribution can be obtained by establishing the linear regression equation.

\section{Results and Discussion}

3.1. Performance Test Results. The workability of concrete directly affects the transportation and pouring of the concrete and may even affect the strength and durability of concrete. The orthogonal test results of the workability are shown in Table 9.

According to Table 9, we can see that the variation range of slump flow is $570-800 \mathrm{~mm}$, which all meet the requirements of the specification. There is not much difference between each group, and on the whole it is at the SF2 $(660-750 \mathrm{~mm})$ level. The first group is at the SF1 (550-655 mm) level, and the seventh group is at the SF3 $(760-850 \mathrm{~mm})$. It is required in the specification that the SF2 level is suitable for ordinary reinforced concrete structures. According to previous studies [33, 34], the content and shape of recycled aggregates and the change of water in the mixture will have an impact on slump flow. Groups 4-6 and 7-9 have an overall gradual decrease in slump flow with the increase of RCA. However, it is not obvious in the 1-3 groups, which is mainly due to the large surface area of RCA and presence of residual mortar tend to absorb more water and to reduce flowability of SCC. And the water correction was done for the absorption of RCA and considered during concrete mixing. At the same time, the different distribution of RCA will have different influences on slump flow.

Yet, a slight reduction in slump flow occurred owing to the adverse physical characteristics (angularity, surface roughness, surface porosity, etc.) of RCA. The RCA used in the present study was more angular than NCA. High absorption capacity of RCA also indirectly suggested that it was more porous and much rougher than NCA due to recycled mortar. The rough-textured RCA particles from Xinjiang increased the harshness of SCC and thus could decrease its slump flow at a greater RCA content. The loss of cement paste into the surface pores of RCA could also decrease the slump flow.

$\mathrm{V}$-funnel flow time ranged from 8.5-23.1 s. A high flow time can be caused by either a low flowing ability or a blockage of the flow [35]. The lack of cohesiveness can cause accumulation of coarse aggregates in the tapered outlet of a $\mathrm{V}$-funnel. Based on Table 9, the first group has the longest flow time, followed by the eighth and second groups. This can lead to arching of coarse aggregates leading to the blockage of concrete flow. Therefore, the high V-funnel flow time was mostly due to its low flowing ability, as perceived from the results of the slump flow test.

The remaining six groups had lower flow times. The shorter flow time indicates the greater flowing ability of concrete [16]. However, a very small flow time does not necessarily give an indication of good flowing ability. In fact, the SCC mixes with a very low V-funnel flow time show excessive bleeding or segregation, thus causing blockage leading to intermittent concrete flow [36]. Also, the SCC mixes with a very high $\mathrm{V}$-funnel flow time are greatly viscous which may exhibit intermittent concrete flow with a reduced flowing ability. High flow time was linked with an excessive viscosity that interrupted the continuous flow of concrete through the lower opening of $\mathrm{V}$-funnel.

The $T_{500}$ slump flow time varied in the range of $3.2-5.2 \mathrm{~s}$. All of them comply with VS1 standard and are suitable for general reinforced concrete structures. According to previous studies [36-38], coarse aggregate had a greater effect on $T_{500}$ slump flow time and reducing the coarse aggregate content had a significant effect on reducing the time. Mainly because the greater surface roughness and angularity of RCA increased the friction, this increase in flow time due to increased viscosity of SCC because RCA content in the mix absorbed more water due to higher porosity. The time difference between nine groups in this paper is not significant, and the main reasons are the range of variation of RCA is not very large and the moderating effect of other variable factors can have an impact on $T_{500}$ slump flow time.

The segregation percent in Table 9 all meet the specification [16], ranging from $8.5 \%$ to $18.5 \%$. The first group meets the SR1 standard, and the remaining eight groups meet the SR2 standard. It can be seen that the first group of RCASCC shows relatively low fluidity and less coarse aggregate content, which is usually conducive to reducing the segregation of SCC. However, aggregate collisions and adverse physical characteristics of RCA may contribute to cause nonuniform distribution of coarse aggregates, which can result the fluidity is significantly low [39]. As a result, the heterogeneity along the depth of concrete might occur during placement, thus leads to a higher segregation percent.

3.2. Analysis of Workability Based on Range Method. Table 10 shows the results of the range analysis for workability, and the impact of various factors on the assessment indicators at different levels can be obtained. As can be seen from Table 10, the order of influence of various factors on slump flow, $\mathrm{V}$-funnel flow time, and $T_{500}$ is as follows: fly ash $>$ W/B $>$ RCA $>$ superplasticizer. For SR, the order is as follows: superplasticizer $>$ fly ash $>$ RCA $>W / B$. In the process of primary selection of optimal factors, $A, C$, and $D$ are well determined. The specific values are $A_{2}$ optimal for $A$, $\mathrm{C}_{3}$ optimal for $\mathrm{C}$, and $\mathrm{D}_{2}$ optimal for $\mathrm{D}$. However, the determination of factor $\mathrm{B}$ requires a comprehensive balance analysis based on the order table and the optimal primary level. The impact of factor B on slump flow, V-funnel flow time, and $\mathrm{T}_{500}$ ranks the third, while its impact on SR ranks last. Therefore, three work performance indicators should be considered first, and then from the preliminary optimal level, it can be seen that $B_{2}$ is the optimal. So, in the case of optimal performance, the optimal ratio is as follows: $\mathrm{A}_{2} \mathrm{~B}_{3} \mathrm{C}_{3} \mathrm{D}_{2}$. 
TABLE 9: Workability test results.

\begin{tabular}{|c|c|c|c|c|c|c|c|c|}
\hline \multirow{2}{*}{ Mix series } & \multicolumn{4}{|c|}{ Factors } & \multicolumn{4}{|c|}{ Workability } \\
\hline & $\mathrm{W} / \mathrm{B}$ & RCA (\%) & Fly ash (\%) & Superplasticizer (\%) & Slump flow $(\mathrm{mm})$ & V-funnel flow time (s) & T500 (s) & SR (\%) \\
\hline 1. $\mathrm{A}_{1} \mathrm{~B}_{1} \mathrm{C}_{1} \mathrm{D}_{1}$ & 0.264 & 30 & 20 & 0.48 & 570 & 23.1 & 5.2 & 18.5 \\
\hline 2. $\mathrm{A}_{1} \mathrm{~B}_{2} \mathrm{C}_{2} \mathrm{D}_{2}$ & 0.264 & 40 & 30 & 0.50 & 710 & 18.0 & 3.9 & 8.9 \\
\hline 3. $\mathrm{A}_{1} \mathrm{~B}_{3} \mathrm{C}_{3} \mathrm{D}_{3}$ & 0.264 & 50 & 40 & 0.52 & 750 & 15.3 & 3.8 & 11.2 \\
\hline 4. $\mathrm{A}_{2} \mathrm{~B}_{1} \mathrm{C}_{2} \mathrm{D}_{3}$ & 0.269 & 30 & 30 & 0.52 & 720 & 8.5 & 3.5 & 8.5 \\
\hline 5. $\mathrm{A}_{2} \mathrm{~B}_{2} \mathrm{C}_{3} \mathrm{D}_{1}$ & 0.269 & 40 & 40 & 0.48 & 740 & 10.2 & 3.8 & 10.1 \\
\hline 6. $\mathrm{A}_{2} \mathrm{~B}_{3} \mathrm{C}_{1} \mathrm{D}_{2}$ & 0.269 & 50 & 20 & 0.50 & 680 & 15.3 & 3.4 & 9.5 \\
\hline 7. $\mathrm{A}_{3} \mathrm{~B}_{1} \mathrm{C}_{3} \mathrm{D}_{2}$ & 0.274 & 30 & 40 & 0.50 & 800 & 9.2 & 3.2 & 9.2 \\
\hline 8. $\mathrm{A}_{3} \mathrm{~B}_{2} \mathrm{C}_{1} \mathrm{D}_{3}$ & 0.274 & 40 & 20 & 0.52 & 600 & 21.2 & 4.5 & 12.1 \\
\hline 9. $\mathrm{A}_{3} \mathrm{~B}_{3} \mathrm{C}_{2} \mathrm{D}_{1}$ & 0.274 & 50 & 30 & 0.48 & 670 & 10.1 & 3.3 & 14.3 \\
\hline
\end{tabular}

TABLE 10: Range method analysis of workability.

\begin{tabular}{|c|c|c|c|c|c|}
\hline \multirow{2}{*}{\multicolumn{2}{|c|}{$\begin{array}{c}\text { Workability } \\
\text { test }\end{array}$}} & \multicolumn{4}{|c|}{ Factors } \\
\hline & & A: W/B & B: RCA & C: fly ash & D: superplasticizer \\
\hline \multirow{7}{*}{$\begin{array}{l}\text { Slump } \\
\text { flow }\end{array}$} & $K_{1}$ & 2030 & 2090 & 1850 & 1980 \\
\hline & $K_{2}$ & 2140 & 2050 & 2100 & 2190 \\
\hline & $K_{3}$ & 2070 & 2100 & 2290 & 2070 \\
\hline & $\overline{K_{1}}$ & 677 & 697 & 617 & 660 \\
\hline & $\overline{K_{2}}$ & 713 & 683 & 700 & 730 \\
\hline & $\overline{K_{3}}$ & 690 & 700 & 763 & 690 \\
\hline & $R$ & 36 & 17 & 146 & 7 \\
\hline \multirow{7}{*}{$\begin{array}{l}\text { V-funnel } \\
\text { flow time }\end{array}$} & $K_{1}$ & 56.4 & 40.8 & 59.6 & 43.4 \\
\hline & $K_{2}$ & 34 & 49.4 & 36.6 & 42.5 \\
\hline & $K_{3}$ & 40.5 & 40.7 & 34.7 & 45 \\
\hline & $\overline{K_{1}}$ & 18.8 & 13.6 & 19.9 & 14.5 \\
\hline & $\overline{K_{2}}$ & 11.3 & 16.5 & 12.2 & 14.2 \\
\hline & $\overline{K_{3}}$ & 13.5 & 13.6 & 11.6 & 15.0 \\
\hline & $R$ & 7.5 & 2.9 & 8.3 & 0.8 \\
\hline \multirow{7}{*}{$T_{500}$} & $K_{1}$ & 12.9 & 11.9 & 13.1 & 12.3 \\
\hline & $K_{2}$ & 10.7 & 12.2 & 10.7 & 10.5 \\
\hline & $K_{3}$ & 11 & 10.5 & 10.8 & 11.8 \\
\hline & $\overline{K_{1}}$ & 4.3 & 4.0 & 4.4 & 4.1 \\
\hline & $\overline{K_{2}}$ & 3.6 & 4.1 & 3.6 & 3.5 \\
\hline & $\overline{K_{3}}$ & 3.7 & 3.5 & 3.6 & 3.9 \\
\hline & $R$ & 0.7 & 0.6 & 0.8 & 0.6 \\
\hline \multirow{7}{*}{ SR } & $K_{1}$ & 38.6 & 36.2 & 40.1 & 42.9 \\
\hline & $K_{2}$ & 28.1 & 31.1 & 31.7 & 27.6 \\
\hline & $K_{3}$ & 35.6 & 35 & 30.5 & 31.8 \\
\hline & $\overline{K_{1}}$ & 12.9 & 12.1 & 13.4 & 14.3 \\
\hline & $\overline{K_{2}}$ & 9.4 & 10.4 & 10.6 & 9.2 \\
\hline & $\overline{K_{3}}$ & 11.9 & 11.7 & 10.2 & 10.6 \\
\hline & $R$ & 3.5 & 1.7 & 3.2 & 5.1 \\
\hline
\end{tabular}

3.3. Strength Test Results. Table 11 shows the results of compressive strength, splitting tensile strength, and axial compressive strength of RCASCC. According to the "Common Concrete Mix Design Specification" (JGJ55-2011) [40], the concrete configuration strength is determined by the following equation, which is used to verify whether the concrete prepared meets the strength grade requirements of the specification:

$$
f_{c u, 0} \geq f_{c u, k}+1.645 \sigma
$$

where $f_{c u, 0}$ is the configuration strength $(\mathrm{MPa}) ; f_{c u, k}$ is the standard value of cubic compressive strength (MPa); and $\sigma$ is the standard deviation of concrete strength (MPa). For $28 \mathrm{~d}$ of compressive strength, according to calculation, the mix of five groups reaches the target strength of C50, and the strength of four groups is slightly lower than the design value. The lowest strength is that of the $A_{2} B_{2} C_{3} D_{1}$ group. RCA has a certain influence on the strength of SCC, and the degree of influence is discrete. The $7 \mathrm{~d}$ compressive strength of the group that reaches the target strength is more than $70 \%$ of the $28 \mathrm{~d}$ compressive strength. For the axial compressive strength, the $28 \mathrm{~d}$ axial compressive strength is between $80 \%$ and $90 \%$ of the $28 \mathrm{~d}$ cubic compressive strength. According to the results of previous tests, it was found that some strength of RCASCC was lower than the anticipated strength $[3,11,39,41]$, while others were higher or the same [7, 24, 42-44]. The main reasons regarding the increase in strength are as follows: the surface roughness of RCA and cement paste strength will improve the bond strength between them; the water absorption capacity of RCA is greater than that of natural aggregate, and the increase of water absorption capacity may reduce the water-binder ratio in the transition zone within the interface; the different water absorption coefficients in RCA and natural aggregate may also have some effects. Primarily, reasons for the decrease in strength are the influence of weaker interface transition zone connection, lower specific gravity, and higher water absorption of RCA compared to the natural aggregates. In addition to the conclusions obtained from the above analysis, we believe that strengths are discrete lies in unevenness of RCA in the configuration process, aggregate types in different regions, and mix design method.

3.4. Modulus of Elasticity. Modulus of elasticity is the main index to evaluate the deformation of concrete, which reflects the ability of concrete to resist deformation. As we can see in Table 11, RCASCC exhibits higher strength than others, which elastic modulus is higher. However, the results also have certain discreteness.

The main reasons are as follows: firstly, the porosity and crushing index of RCA are higher than those of NCA. There are a large number of microcracks or other defects in the internal and surface of RCA, leading to its lower elastic modulus than NCA [45], which has been proved in many 
TABLE 11: Mechanical properties test results.

\begin{tabular}{|c|c|c|c|c|c|}
\hline \multirow{2}{*}{ Mix series } & \multicolumn{5}{|c|}{ Mechanical properties } \\
\hline & $7 \mathrm{~d} f_{c u}(\mathrm{MPa})$ & $28 \mathrm{~d} f_{c u}(\mathrm{MPa})$ & $28 \mathrm{~d} f_{t s}(\mathrm{MPa})$ & $28 \mathrm{~d} f_{c p}(\mathrm{MPa})$ & $E_{c}(\mathrm{GPa})$ \\
\hline 1. $\mathrm{A}_{1} \mathrm{~B}_{1} \mathrm{C}_{1} \mathrm{D}_{1}$ & 38.61 & 62.28 & 4.61 & 49.52 & 30.1 \\
\hline 2. $\mathrm{A}_{1} \mathrm{~B}_{2} \mathrm{C}_{2} \mathrm{D}_{2}$ & 42.43 & 62.77 & 4.51 & 52.24 & 33.8 \\
\hline 3. $\mathrm{A}_{1} \mathrm{~B}_{3} \mathrm{C}_{3} \mathrm{D}_{3}$ & 36.45 & 57.20 & 3.9 & 51.91 & 29.4 \\
\hline 4. $\mathrm{A}_{2} \mathrm{~B}_{1} \mathrm{C}_{2} \mathrm{D}_{3}$ & 46.89 & 61.46 & 4.38 & 52.88 & 34.3 \\
\hline 5. $\mathrm{A}_{2} \mathrm{~B}_{2} \mathrm{C}_{3} \mathrm{D}_{1}$ & 40.04 & 51.72 & 4.52 & 48.11 & 28.9 \\
\hline 6. $\mathrm{A}_{2} \mathrm{~B}_{3} \mathrm{C}_{1} \mathrm{D}_{2}$ & 40.89 & 58.48 & 4.22 & 50.61 & 29.6 \\
\hline 7. $\mathrm{A}_{3} \mathrm{~B}_{1} \mathrm{C}_{3} \mathrm{D}_{2}$ & 43.70 & 63.15 & 4.47 & 49.81 & 30.5 \\
\hline 8. $\mathrm{A}_{3} \mathrm{~B}_{2} \mathrm{C}_{1} \mathrm{D}_{3}$ & 44.91 & 63.05 & 4.68 & 49.25 & 31.9 \\
\hline 9. $\mathrm{A}_{3} \mathrm{~B}_{3} \mathrm{C}_{2} \mathrm{D}_{1}$ & 40.12 & 56.47 & 3.81 & 52.42 & 28.7 \\
\hline
\end{tabular}

research studies [8, 46-48]. Beshr et al. [49] and Stock et al. [50] concluded through experiments that the higher the modulus of elasticity of the coarse aggregate species, the higher the modulus of elasticity of the concrete in the same water-binder ratio. $\mathrm{Wu}$ et al. [51] obtained a similar point through the application of high-strength and performance concrete aggregates. Therefore, for HPC mixed with recycled aggregates, the relative size of elastic modulus of recycled aggregates did have a certain influence on the results. The main reason for the discreteness of the results may be the randomness of the selection of recycled aggregates. Secondly, the shape of RCA affected the elastic modulus. Li [52] found that the elastic modulus of crushed stone concrete was significantly higher than that of pebble concrete by exploring the shape of different coarse aggregates. The reason was that in addition to the interface effect, the difference in elastic modulus between limestone crushed stone and pebble coarse aggregate was one of the important factors. In this paper, the shape of RCA in Xinjiang is mainly the pebble shape, so to some extent, the relative magnitude of the elastic modulus will also have a certain influence.

3.5. Analysis of Mechanical Properties Based on Range Method. Table 12 shows the results of mechanical properties calculated by the range method. According to comprehensive balance analysis, factor $A$ was selected between $A_{1}$ and $A_{3}$. Calculations found that $A_{1}$ and $A_{3}$ had little effect on $28 \mathrm{~d} f_{c u}$. When choosing $\mathrm{A}_{1}$, both $28 \mathrm{~d} f_{c u}$ and $E_{c}$ increased by $1.4 \%$ and $2.4 \%$ compared with $\mathrm{A}_{3}$, so $\mathrm{A}_{1}$ was selected. Through the comparison between $B_{1}$ and $B_{2}$, when $\mathrm{B}_{1}$ was selected, $7 \mathrm{~d} f_{c u}$ and $28 \mathrm{~d} f_{c u}$ were $1.41 \%$ and $5 \%$ more than $\mathrm{B}_{2}$, however, $28 \mathrm{~d} f_{t s}$ in the reduction of $1.7 \%$, so choose $B_{1} ; C_{2}$ was the main factor level in both $28 \mathrm{~d} f_{c p}$ and $E_{c}$, so it was directly selected; It was found that the effects of $\mathrm{D}_{2}$ and $\mathrm{D}_{3}$ on $7 \mathrm{~d} f_{c u}, 28 \mathrm{~d} f_{c u}, 28 \mathrm{~d} f_{c p}$, and $E_{c}$ were very small. So, $\mathrm{D}_{2}$ and $\mathrm{D}_{3}$ can both be selected, $\mathrm{D}_{2}$ was chosen ultimately.

3.6. Determination of the Optimal Mix. The optimal mix has been determined considering the workabilities and mechanical properties of RCASCC comprehensively. Under the influence of multiple factors, the influence of water-binder ratio on mechanical properties is greater than that on workabilities. Therefore, the water-binder ratio was analyzed
TABLE 12: Range method analysis of mechanical properties.

\begin{tabular}{|c|c|c|c|c|c|}
\hline \multirow{2}{*}{\multicolumn{2}{|c|}{ Experiment }} & \multicolumn{4}{|c|}{ Factors } \\
\hline & & A: W/B & B: RCA & C: fly ash & D: superplasticizer \\
\hline \multirow{7}{*}{$7 \mathrm{~d} f_{c u}$} & $K_{1}$ & 117.48 & 129.20 & 124.41 & 118.77 \\
\hline & $K_{2}$ & 127.82 & 127.38 & 129.44 & 127.02 \\
\hline & $K_{3}$ & 128.73 & 117.46 & 120.19 & 128.25 \\
\hline & $\overline{K_{1}}$ & 39.16 & 43.07 & 41.47 & 39.59 \\
\hline & $\frac{1}{K_{2}}$ & 42.61 & 42.46 & 43.15 & 42.34 \\
\hline & $\frac{2}{K_{3}}$ & 42.91 & 39.15 & 40.06 & 42.75 \\
\hline & $R$ & 3.75 & 3.92 & 3.09 & 3.16 \\
\hline \multirow{7}{*}{$28 \mathrm{~d} f_{c u}$} & $K_{1}$ & 182.25 & 186.89 & 183.81 & 170.47 \\
\hline & $K_{2}$ & 171.66 & 177.54 & 180.70 & 184.40 \\
\hline & $K_{3}^{2}$ & 182.67 & 172.15 & 172.07 & 181.71 \\
\hline & $\overline{K_{1}}$ & 60.75 & 62.30 & 61.27 & 56.82 \\
\hline & $\frac{1}{K_{2}}$ & 57.22 & 59.18 & 60.23 & 61.47 \\
\hline & $\overline{K_{3}}$ & 60.89 & 57.38 & 57.36 & 60.57 \\
\hline & $R$ & 3.67 & 4.92 & 3.91 & 4.65 \\
\hline \multirow{7}{*}{$28 \mathrm{~d} f_{t s}$} & $K_{1}$ & 13.02 & 13.46 & 13.51 & 12.94 \\
\hline & $K_{2}$ & 13.12 & 13.71 & 12.7 & 13.2 \\
\hline & $K_{3}^{2}$ & 12.96 & 11.93 & 12.89 & 12.96 \\
\hline & $\overline{K_{1}}$ & 4.34 & 4.49 & 4.50 & 4.31 \\
\hline & $\overline{K_{2}}$ & 4.37 & 4.57 & 4.23 & 4.40 \\
\hline & $\overline{K_{3}}$ & 4.32 & 3.98 & 4.30 & 4.32 \\
\hline & $R$ & 0.05 & 0.59 & 0.27 & 0.09 \\
\hline \multirow{7}{*}{$28 \mathrm{~d} f_{c p}$} & $K_{1}$ & 153.67 & 152.21 & 149.38 & 154.82 \\
\hline & $K_{2}$ & 151.6 & 149.6 & 157.54 & 152.66 \\
\hline & $K_{3}$ & 151.48 & 154.94 & 149.83 & 154.04 \\
\hline & $\overline{K_{1}}$ & 51.22 & 50.74 & 49.79 & 51.61 \\
\hline & $\overline{K_{2}}$ & 50.53 & 49.87 & 52.51 & 50.89 \\
\hline & $\overline{K_{3}}$ & 50.49 & 51.65 & 49.94 & 51.35 \\
\hline & $R$ & 0.73 & 1.78 & 2.72 & 0.72 \\
\hline \multirow{7}{*}{$E_{c}$} & $K_{1}$ & 93.3 & 94.9 & 91.6 & 87.7 \\
\hline & $K_{2}$ & 92.8 & 94.6 & 96.8 & 93.9 \\
\hline & $K_{3}$ & 91.1 & 87.7 & 88.8 & 95.6 \\
\hline & $\overline{K_{1}}$ & 31.10 & 31.63 & 30.53 & 29.23 \\
\hline & $\frac{1}{K_{2}}$ & 30.93 & 31.53 & 32.27 & 31.30 \\
\hline & $\overline{K_{3}}$ & 30.37 & 29.23 & 29.60 & 31.87 \\
\hline & $R$ & 0.73 & 2.4 & 2.67 & 2.64 \\
\hline
\end{tabular}

under the condition that the strength condition was satisfied, and $A_{1}$ and $A_{2}$ can be used. However, when the water-binder ratio reaches $A_{2}$, better workability is exhibited. When the RCA content was chosen $B_{1}$, the mechanical properties and workabilities were the best, which is similar to the result analysis method of Limbachiya et al. [53] and Lavado et al. [54]. The effect of fly ash on slump flow is far greater than 
other indicators. As one of the significantly affected work performance indicators, $\mathrm{C}_{3}$ was finally chosen as the main consideration. Combining the consistency of workability and mechanical properties, $\mathrm{D}_{2}$ was selected.

Through comprehensive analysis, the optimal mix to satisfy the mechanical properties and workabilities is as follows: $\mathrm{A}_{2} \mathrm{~B}_{1} \mathrm{C}_{3} \mathrm{D}_{2}$. (water-binder ratio, 0.269; recycled coarse aggregate replacement rate, $30 \%$; fly ash substitution ratio, $40 \%$; and superplasticizer content, $0.50 \%$ ).

Mechanical property and workability tests were carried out to verify whether the optimal mix satisfies the requirements of C50. The results are shown in Table 13.

\subsection{Microtest Result Analysis}

3.7.1. Aperture Distribution Characteristics. The aperture structure distribution diagram of concrete shows in detail the internal pore distribution of the range. Aperture size distribution diagrams of RCASCC with nine groups are shown in Figure 5.

The internal structure of concrete represented by its pore system, i.e., the porosity and pore size distribution, plays a decisive role in influencing the physical and mechanical properties of concrete [55]. The figure shows that the overall trends of aperture distribution of the nine groups of concrete are approximately the same, but some differences exist in the proportion of each aperture size range. The concrete surface has many large pores. From the beginning of the mercury intrusion process, the nine groups of curves generally show a decreasing trend, indicating that as the amount of mercury intrusion increases, the pores on the concrete surface gradually decrease. It is also widely accepted that there is an inverse correlation between the volume of pores and the levels of stress to which the concrete can be subjected, and this relationship should also be taken into account [56-58].

When the aperture range reaches approximately $10000 \mathrm{~nm}$, the nine groups of curves begin to fluctuate to different degrees, among which the peak fluctuations of the first, the fourth, and the eighth group are the most evident. With the increase in mercury intrusion, each group of curves has the largest fluctuation in the aperture diameter range of $100-10000 \mathrm{~nm}$, in which the distribution of each pore size is uneven. In the seventh curve, with the gradual increase of mercury, the pore diameter range gradually decreases. However, the number of pores gradually increases in general. According to porosity results, the porosity of the seventh group is the largest, which is $14.54 \%$. In the case of similar distribution of other aperture sizes, the increasing trend of mercury intrusion in the pores of the seventh group explains the phenomenon that the porosity is the largest. Except for the eighth group, the maximum peak of the curves of the other eight groups appears in the aperture diameter range of $1-100 \mathrm{~nm}$. However, the peak point of the fifth, seventh, and ninth groups are relatively high, indicating that the fine pores accounted for the most number. The porosity of these groups of concrete is also significantly higher than that of other groups.
3.7.2. Relationship between Porosity and Strengths. Porosity is a first-order variable which inversely influences the mechanical properties of cementitious composites [41]. According to the test results, the relationship between the microstructure and macromechanics of RCASCC is preliminarily analyzed from the change in the porosity of pore structure and strength of mechanical properties. The porosity of nine groups of RCASCC was fitted with the test data of compressive strength and tensile strength (Figure 6), and the fitting results are shown in Table 14.

As shown in Figure 6, the data have low discreteness. The results of both fittings show a monotonic decreasing trend, thereby indicating that porosity and strength are negatively correlated. The relationship between porosity and compressive strength remains consistent with the trend derived by Barnhouse and Srubar [59] and Gómez-Soberón [60]. However, there are differences in other numerical factors such as the slope of the curve depending on factors such as different mix of the concrete. In general, porosity has a correlation with strength. Porosity can be used to reflect the relative size of compressive strength and tensile strength. Meanwhile, increases in bulk volume of aggregate, or the use of larger aggregates, were also reported to increase the porosity and decrease the compressive strength and modulus of elasticity of pervious concrete. This loss in mechanical properties was attributed to a decrease in paste content at higher aggregate volumes [61]. The reason for the results is the relatively small change in four factors at three levels, probably leading to low data dispersion and relatively good fitting effect. In addition, the strength of concrete is affected by multiple factors, such as aggregate strength and ambient temperature. Porosity is only the product of cement hardening process. In summary, the strength of RCASCC depends on the change in internal porosity to a certain extent. With known porosity, the relative size of tensile strength and compressive strength can be roughly determined.

3.7.3. Fractal Characteristics of Apertures. MIP was used to test the nine groups of RCASCC. The linear relationship of $\log u-\log \left(r / r_{\text {max }}\right)$ was determined according to the test data of aperture size and the amount of mercury intrusion. Then, $D$ was calculated by the formula in 2.3.5. The partial fitting results of $\log u-\log \left(r / r_{\max }\right)$ are shown in Figure 7 . Table 15 shows the calculation results of fractal dimension $D$ of RCASCC of nine groups.

As shown in Table 15, the fractal dimension $D$ of each group is between 2 and 3 . The overall correlation coefficient of $D$ is relatively high, at approximately 0.90 . This finding indicates that the pore structure of RCASCC has the fractal characteristics of irregular shape, which has been demonstrated in previous studies, such as SCC, asphalt concrete, and pumice concrete [62-64]. These studies illustrated the applicability of fractal theory to the analysis of concrete materials. Figure 8 and Table 16 show the relationship between $D$ and strength. The correlation is better when using polynomial to fit strength and fractal dimension $D$. Strength is negatively correlated with porosity. The larger fractal 
TABLE 13: Results of the optimal mix test.

\begin{tabular}{|c|c|c|c|c|c|c|}
\hline \multicolumn{4}{|c|}{ Work abilities } & \multicolumn{3}{|c|}{ Mechanical properties } \\
\hline Slump flow $(\mathrm{mm})$ & V-funnel flow time (s) & $T_{500}(\mathrm{~s})$ & SR (\%) & $28 \mathrm{~d} f_{c u}(\mathrm{MPa})$ & $28 \mathrm{~d} f_{t s}(\mathrm{MPa})$ & $28 \mathrm{~d} f_{c p}(\mathrm{MPa})$ \\
\hline 670 & 10.2 & 3.8 & 12.5 & 62.21 & 4.79 & 50.05 \\
\hline
\end{tabular}

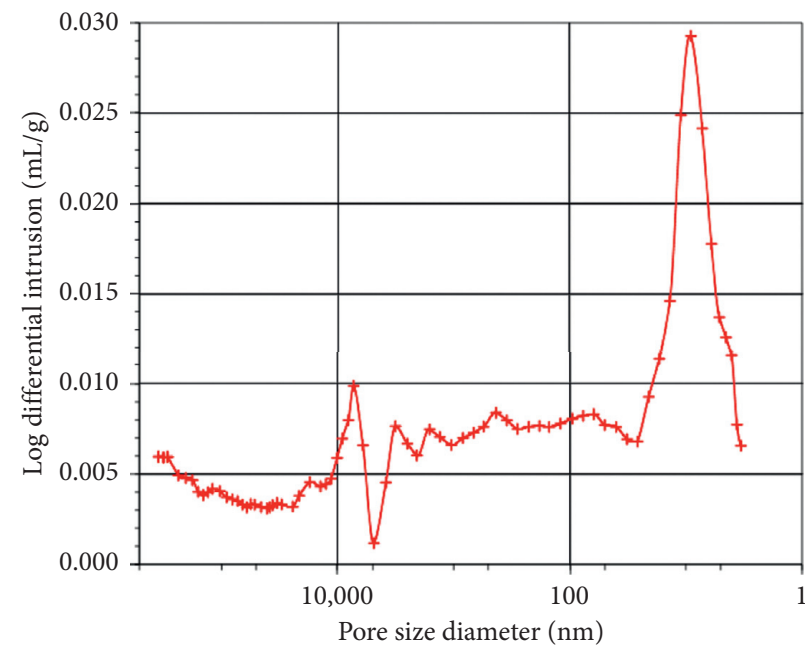

। Intrusion for cycle 1

(a)

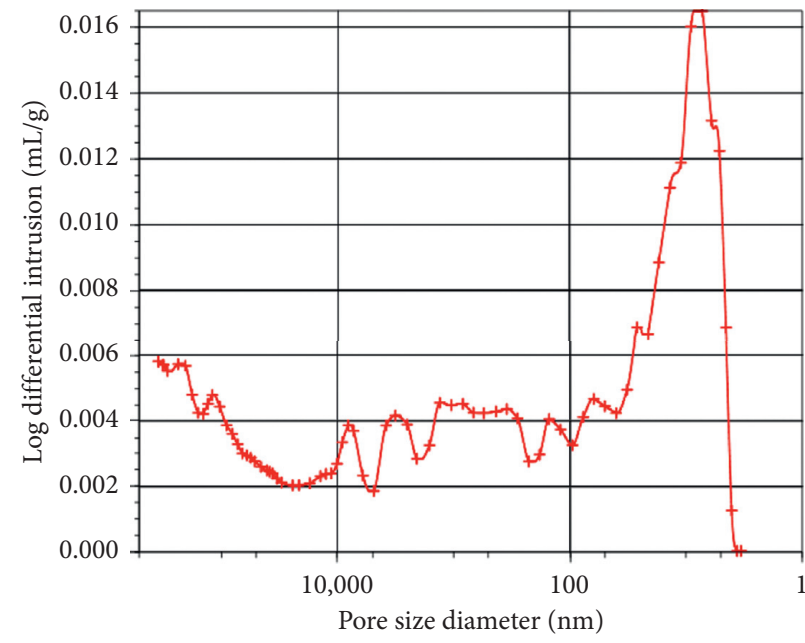

— Intrusion for cycle 1

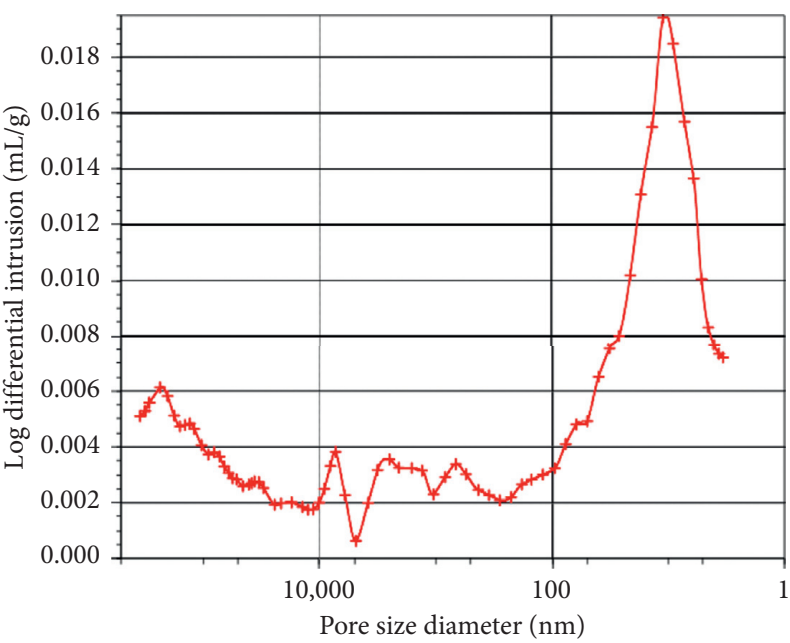

$\multimap$ Intrusion for cycle 1

(b)

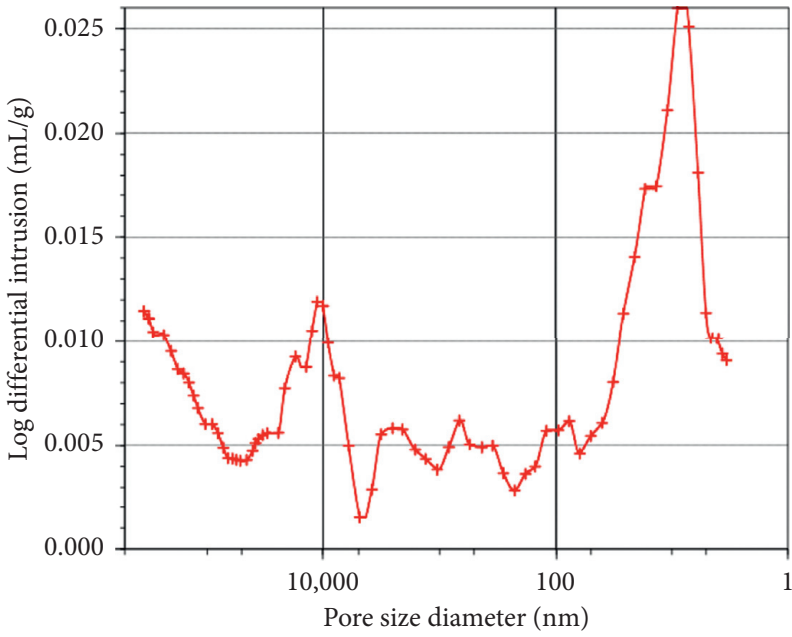

— Intrusion for cycle 1

Figure 5: Continued. 


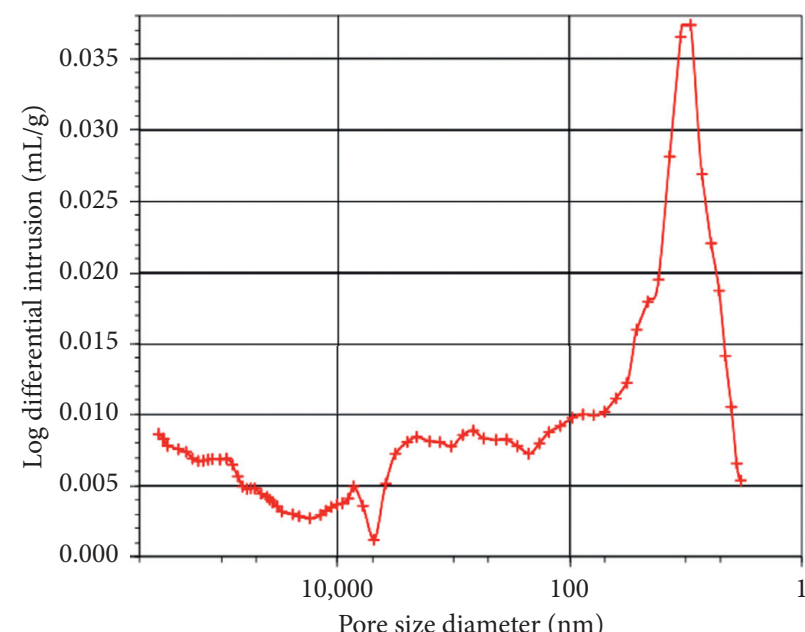

$\uparrow$ Intrusion for cycle 1

(e)

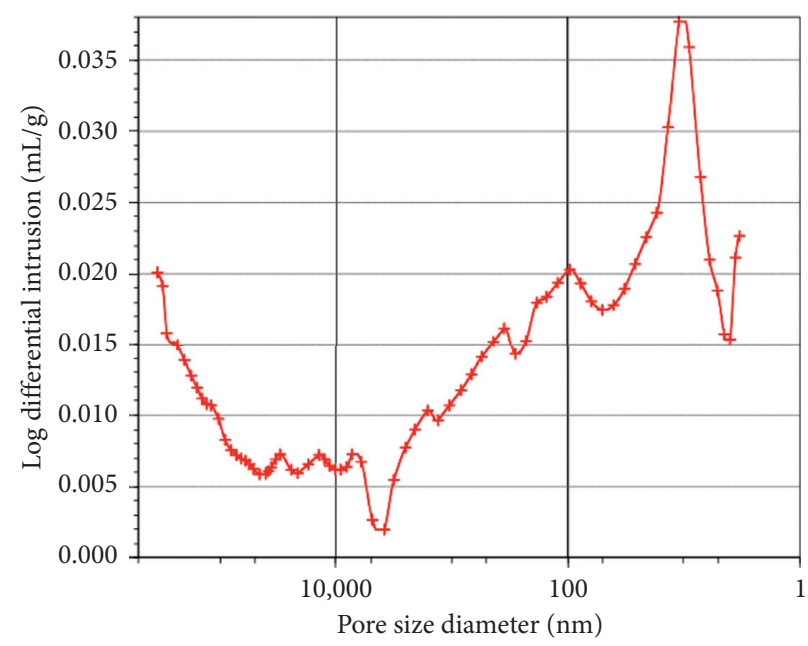

+ Intrusion for cycle 1

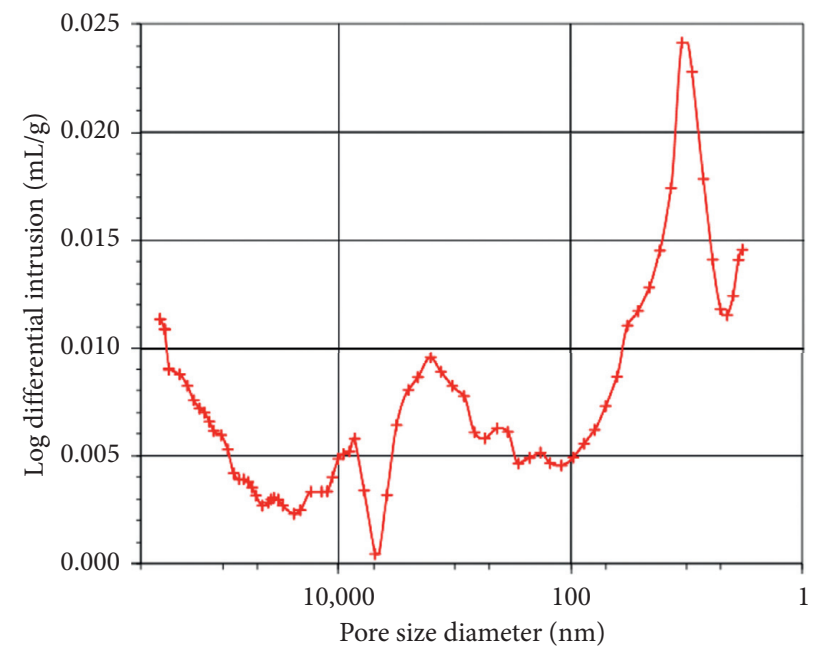

$\leftarrow$ Intrusion for cycle 1

(f)

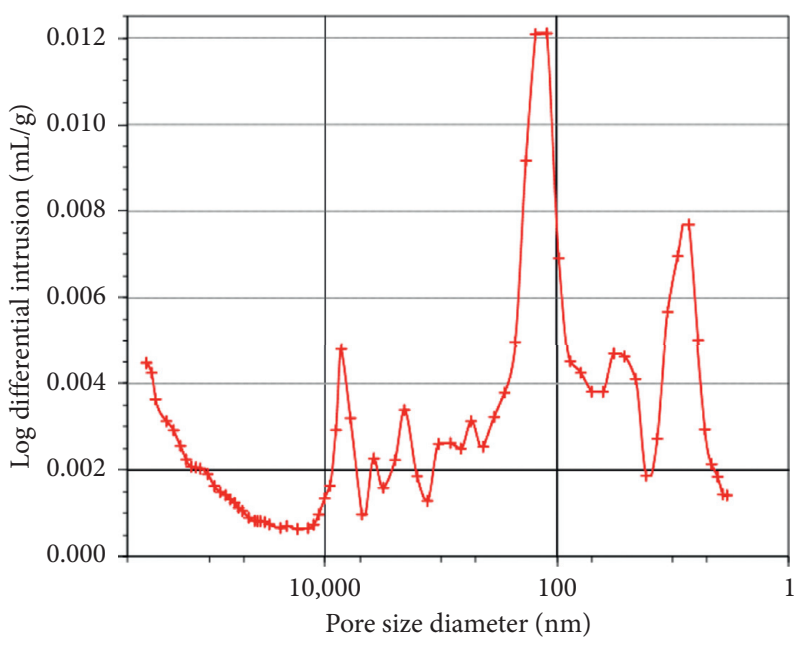

- Intrusion for cycle 1

(h)

(g)

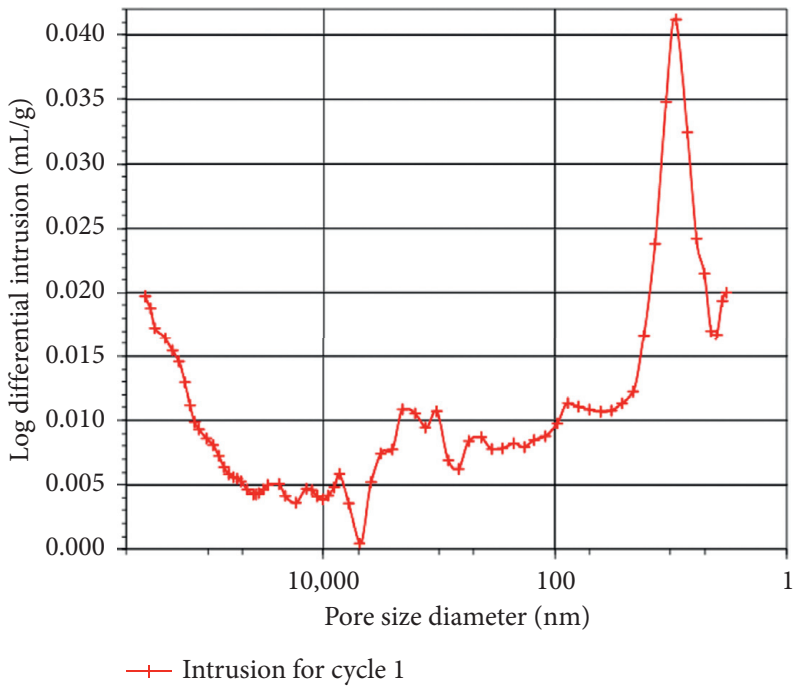

(i)

Figure 5: Aperture distribution diagrams. (a) $A_{1} B_{1} C_{1} D_{1}$, (b) $A_{1} B_{2} C_{2} D_{2}$, (c) $A_{1} B_{3} C_{3} D_{3}$, (d) $A_{2} B_{1} C_{2} D_{3}$, (e) $A_{2} B_{2} C_{3} D_{1}$, (f) $A_{2} B_{3} C_{1} D_{2}$, (g) $\mathrm{A}_{3} \mathrm{~B}_{1} \mathrm{C}_{3} \mathrm{D}_{2}$, (h) $\mathrm{A}_{3} \mathrm{~B}_{2} \mathrm{C}_{1} \mathrm{D}_{3}$, and (i) $\mathrm{A}_{3} \mathrm{~B}_{3} \mathrm{C}_{2} \mathrm{D}_{1}$. 


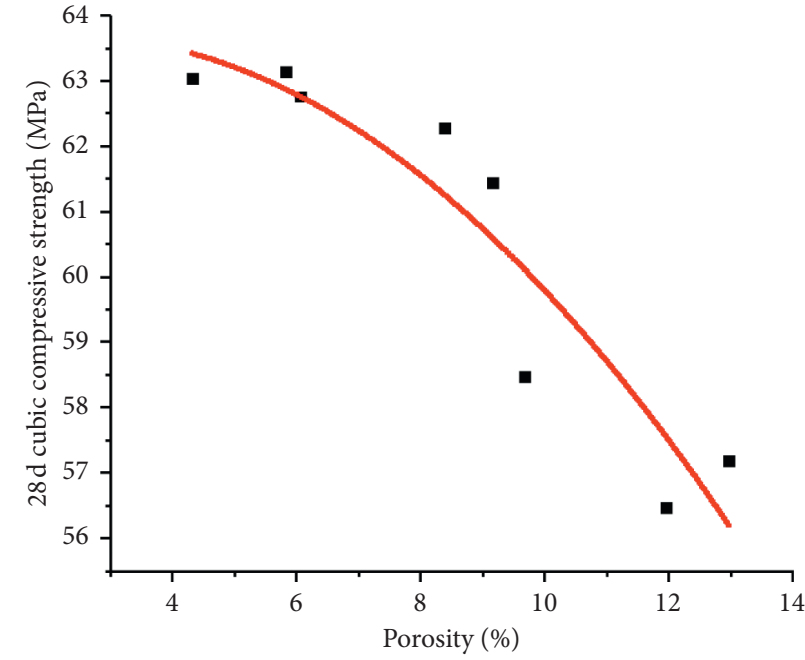

(a)

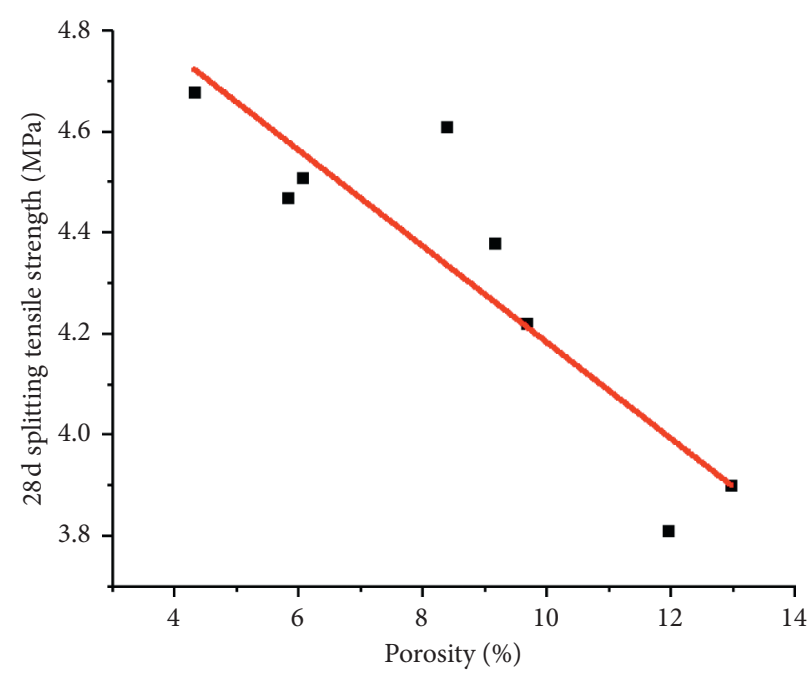

(b)

FIGURE 6: Graphs of porosity and strength. (a) Graph of porosity and compressive strength. (b) Graph of porosity and tensile strength.

TABLE 14: Fitting results of mathematical expressions of porosity and strength.

\begin{tabular}{lccc}
\hline Type & Fitting model & Results & $R^{2}$ \\
\hline$a$ & $y=a x^{2}+b x+c$ & $y=-0.0659 x^{2}+0.3044 x+63.341$ & 0.823 \\
$b$ & $y=a x+b$ & $y=-0.095 x+5.134$ & 0.774 \\
\hline
\end{tabular}

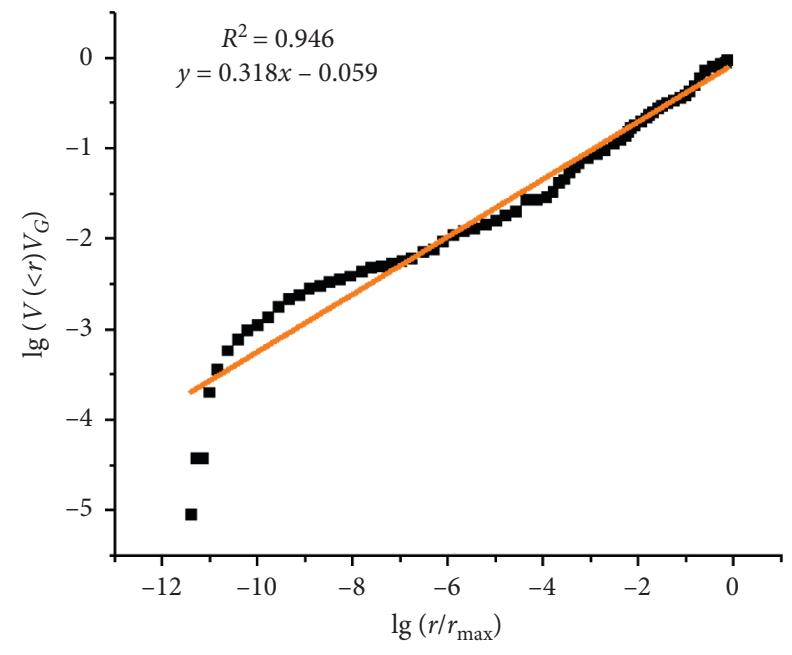

(a)

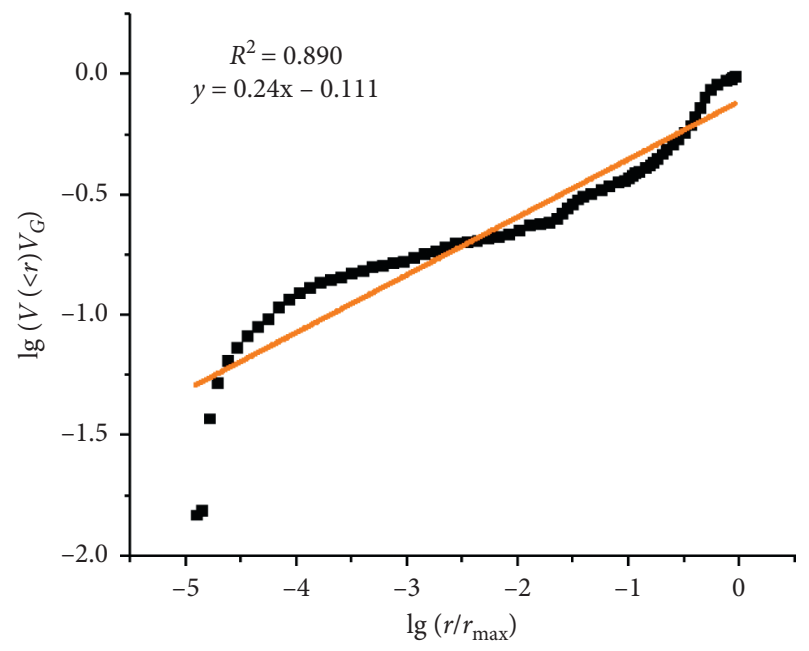

(b)

FIgURe 7: Fractal dimension fitting of apertures of RCASCC with different mixes. (a) $A_{1} B_{1} C_{1} D_{1}$ and (b) $A_{1} B_{2} C_{2} D_{2}$.

TABLE 15: Fractal dimension of pore volume of RCASCC.

\begin{tabular}{lcr}
\hline Mix series & Fractal dimension $D$ & $R^{2}$ \\
\hline 1. $\mathrm{A}_{1} \mathrm{~B}_{1} \mathrm{C}_{1} \mathrm{D}_{1}$ & 2.682 & 0.946 \\
2. $\mathrm{A}_{1} \mathrm{~B}_{2} \mathrm{C}_{2} \mathrm{D}_{2}$ & 2.744 & 0.890 \\
3. $\mathrm{A}_{1} \mathrm{~B}_{3} \mathrm{C}_{3} \mathrm{D}_{3}$ & 2.782 & 0.938 \\
4. $\mathrm{A}_{2} \mathrm{~B}_{1} \mathrm{C}_{2} \mathrm{D}_{3}$ & 2.747 & 0.911 \\
5. $\mathrm{A}_{2} \mathrm{~B}_{2} \mathrm{C}_{3} \mathrm{D}_{1}$ & 2.712 & 0.909 \\
6. $\mathrm{A}_{2} \mathrm{~B}_{3} \mathrm{C}_{1} \mathrm{D}_{2}$ & 2.761 & 0.931 \\
7. $\mathrm{A}_{3} \mathrm{~B}_{1} \mathrm{C}_{3} \mathrm{D}_{2}$ & 2.736 & 0.929 \\
8. $\mathrm{A}_{3} \mathrm{~B}_{2} \mathrm{C}_{1} \mathrm{D}_{3}$ & 2.722 & 0.912 \\
9. $\mathrm{A}_{3} \mathrm{~B}_{3} \mathrm{C}_{2} \mathrm{D}_{1}$ & 2.794 & 0.918 \\
\hline
\end{tabular}




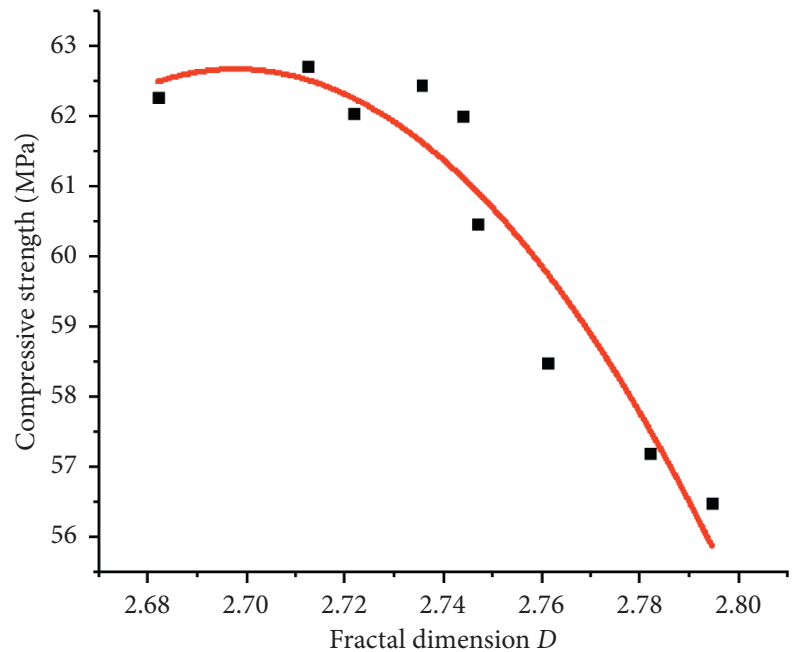

(a)

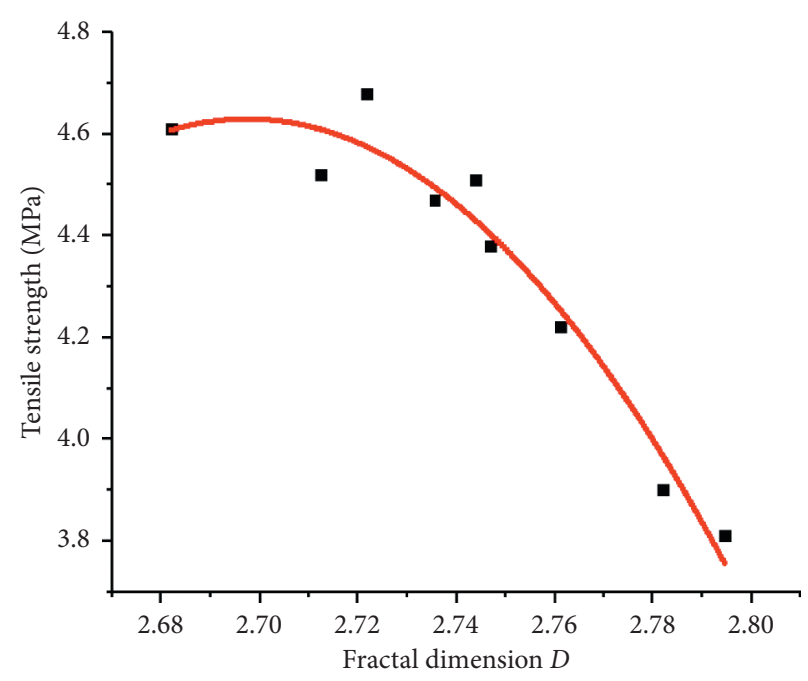

(b)

FIgURE 8: Graphs of $D$ and strength. (a) Graph of $D$ and compressive strength. (b) Graph of $D$ and tensile strength.

TABle 16: Fitting results of mathematical expressions of $D$ and strength.

\begin{tabular}{lccc}
\hline Type & Fitting model & Results & $R^{2}$ \\
\hline$a$ & $y=a x^{2}+b x+c$ & $y=-726.486 x^{2}+3919.638 x-5224.26$ & 0.892 \\
$b$ & $y=a x^{2}+b x+c$ & $y=-670.253 x^{2}+500.387 x-92.752$ & 0.938 \\
\hline
\end{tabular}

dimension $D$ indicates more complex pore structure of concrete. Complex pore structure adversely affects the strength, which in return decreases with the increase in the fractal dimension $D$. According to the fitting results of RCASCC, the relative strength can be approximately judged by the fractal dimension $D$.

\section{Conclusions}

The orthogonal test method was used to analyze the mix of C50 RCASCC from two angles of workabilities and mechanical properties to obtain the optimal mix. Then, nine groups of concrete were studied by MIP. Finally, the correlation between macromechanical properties and microMIP results was analyzed. The specific results are as follows:

(1) RCA in Xinjiang can be used to produce RCASCC that satisfies the strength requirements of C50. However, the data have certain discreteness. The optimal mix is as follows: water-binder ratio of 0.269 , recycled coarse aggregate replacement rate of 30\%, fly ash substitution ratio of $40 \%$, and superplasticizer content of $0.50 \%$.

(2) The pore structure distribution diagrams show that the overall trend of aperture diameter distribution of the nine groups of RCASCC is roughly the same, but the proportion of aperture diameter range has some differences. The relative value of porosity can be roughly inferred from the results of aperture distribution curves.
(3) By fitting the porosity with strengths, the discreteness of data is relatively low, and the fitting effect is good. Porosity is negatively correlated with compressive strength and tensile strength. In accordance with porosity, tensile strength and compressive strength can be approximated.

(4) The fractal dimension $D$ of the nine groups is between 2 and 3. Slight difference is observed, and the correlation is good. The larger $D$ indicates more complex pore structure of concrete, thereby shows that the pore structure of RCASCC has the fractal characteristics of irregular shape. Complex pore structures can affect strength adversely by polynomial fitting with compressive strength and tensile strength.

\section{Data Availability}

The research data used to support the findings of this study are available from the corresponding author upon request.

\section{Conflicts of Interest}

The authors declare that there are no conflicts of interest regarding the publication of this paper.

\section{Acknowledgments}

This research was supported by the National Natural Science Foundation of China (51768069). 


\section{References}

[1] M. J. Mcginnis, M. Davis, A. de la Rosa, B. D. Weldon, and Y. C. Kurama, "Strength and stiffness of concrete with recycled concrete aggregates," Construction and Building Materials, vol. 154, pp. 258-269, 2017.

[2] K. Ozawa, K. Maekawa, M. Kunishima, and H. Okamuura, "Development of high performance concrete bases on durability design of concrete structures," Proceedings of the Second East-Asia and Pacific Conference on Structural Engineering and Construction (EASEC-2), vol. 1, pp. 445-450, 1989.

[3] M. Tuyan, A. Mardani-Aghabaglou, and K. Ramyar, "Freezethaw resistance, mechanical and transport properties of selfconsolidating concrete incorporating coarse recycled concrete aggregate," Materials \& Design, vol. 53, pp. 983-991, 2014.

[4] P. K. Mehta, "Concrete: microstructure, properties, and materials," Prentice Hall International, vol. 13, no. 4, p. 499, 2006.

[5] H. Yang, D. Liang, Z. Deng, and Y. Qin, "Effect of limestone powder in manufactured sand on the hydration products and microstructure of recycled aggregate concrete," Construction and Building Materials, vol. 188, pp. 1045-1049, 2018.

[6] J. Xiao, "New progress in research of recycled concrete materials and structures," World Science, vol. 12, pp. 29-31, 2006, in Chinese.

[7] J. Xiao, J. Li, and C. Zhang, "Mechanical properties of recycled aggregate concrete under uniaxial loading," Cement and Concrete Research, vol. 35, no. 6, pp. 1187-1194, 2004.

[8] R. V. Silva, J. de Brito, and R. K. Dhir, "Properties and composition of recycled aggregates from construction and demolition waste suitable for concrete production," Construction and Building Materials, vol. 65, pp. 201-217, 2014.

[9] J. Xiao, J. Li, and Y. Lan, "The latest progress and review of recycled concrete techno-logy," Concrete, vol. 10, pp. 17-20, 2003, in Chinese.

[10] I. González-Taboada, B. González-Fonteboa, F. MartínezAbella, and N. Roussel, "Robust-ness of self-compacting recycled concrete: analysis of sensitivity parameters," Materials and Structures, vol. 51, no. 1, p. 8, 2018.

[11] L. A. Pereira-de-Oliveira, M. C. S. Nepomuceno, J. P. CastroGomes, and M. F. C. Vila, "Permeability properties of selfcompacting concrete with coarse recycled aggregates," Construction and Building Materials, vol. 51, pp. 113-120, 2014.

[12] E. Güneyisi, M. Gesoğlu, Z. Algın, and H. Yazıcı, "Effect of surface treatment methods on the properties of self-compacting concrete with recycled aggregates," Construction and Building Materials, vol. 64, pp. 172-183, 2014.

[13] P. L. Domone, "Self-compacting concrete: an analysis of 11 years of case studies," Cement and Concrete Composites, vol. 28, no. 2, pp. 197-208, 2006.

[14] H. Okamura and M. Ouchi, "Self-compacting high performance concrete," Progress in Structural Engineering and Materials, vol. 1, no. 4, pp. 378-383, 1998.

[15] Japanese Ready-Mix Concrete Association, Manual of Producing High Fluidity Concrete, Japanese Ready-Mixed Concrete Association, Tokyo, Japan, 1998.

[16] F. D. Larrard, "Concrete mixture proportioning," Information Storage and Retrieval, vol. 4, no. 2, pp. 113-131, 2017.

[17] H. W. Chai, Design and Testing of Self-Compacting concrete, Department of Civil and Envi-ronmental Engineering, University College London, London, UK, 1998.
[18] S. Basavarajappat, "Wear studies on metal matrix composites: a Taguchi approach," Journal of Material Science Technology, vol. 21, no. 6, pp. 845-850, 2005.

[19] X. Zhang, Experimental Study of Self-Compacting Light-Aggregate concrete, Dalian Univer-sity of Technology, Dalian, China, 2008, in Chinese.

[20] G. Taguchi, "Table of orthogonal arrays and linear graphs," Reports of Statistical Applications Research, Union of Japanese. Scientists and Engineers, vol. 64, pp. 1-43, 1960.

[21] X. Jun, Y. Ding, and M. Cao, "Research progress on the design of self-compacting concrete ratio," Concrete, vol. 8, no. 286, pp. 105-109, 2013, in Chinese.

[22] V. D. Prasad, E. L. Prakash, M. Abishek, K. Ushanth Dev, and C. K. Sanjay Kiran, "Study on concrete containing waste foundry sand, fly ash and polypropylene fibre using Taguchi method," Materials Today: Proceedings, vol. 5, no. 11, pp. 23964-23973, 2018.

[23] S. I. Mohammed and K. B. Najim, "Mechanical strength, flexural behavior and fracture energy of recycled concrete aggregate self-compacting concrete," Structure, vol. 23, pp. 34-43, 2020.

[24] E. Ozbay, A. Oztas, A. Baykasoglu, and H. Ozbebek, "Investigating mix proportions of high strength self compacting concrete by using Taguchi method," Construction and Building Materials, vol. 23, no. 2, pp. 694-702, 2009.

[25] Q. Liu, F. Han, G. Yu, and P. Xu, "Basic mechanical properties of recycled coarse aggregate self-compacting concrete," Journal of Building Materials, vol. 23, no. 5, pp. 65-72, 2020, in Chinese.

[26] China Ministry of Construction, Chinese Standard GB/ T25177-2010, Recycled Coarse Aggregate for Concrete, China Ministry of Construction, Beijing, China, 2010.

[27] China Ministry of Construction, Chinese Standard JGJ522006, Standard for Quality and Inspection Method of Sand and Stone for Common Concrete, China Ministry of Construction, Beijing, China, 2006.

[28] China Ministry of Construction, Chinese Standard CECS 203: 2006, Technical Specification for Application of Self-Compacting Concrete, China Ministry of Construction, Beijing, China, 2006.

[29] China Ministry of Construction, Chinese Standard JGJ/T2832012, Technical Specification for Application of Self-Compacting Concrete, China Ministry of Construction, Beijing, China, 2012.

[30] China Ministry of Construction, Chinese Standard GB/ T50081-2019, Standard Test Method for Physical and Mechanical Properties of Concrete, China Ministry of Construction, Beijing, China, 2019.

[31] B. B. Mandelbrot, "Negative fractal dimensions and multifractals," Physica A: Statistical Mechanics and Its Applications, vol. 163, no. 1, pp. 306-315, 1990.

[32] X. Cao, Study on the Variation Rule of Pore Structure of Natural Pumice Concrete Based on NMR Technology, Inner Mongolia University of Technology, Hohhot, China, 2020.

[33] P. Revathi, R. S. Selvi, and S. S. Velin, "Investigations on fresh and hardened properties of recycled aggregate self-compacting concrete," Journal of the Institution of Engineers, vol. 94, no. 3, pp. 179-185, 2013.

[34] K. Kapoor, S. P. Singh, B. Singh, and P. Singh, "Effect of recycled aggregates on fresh and hardened properties of self compacting concrete," Materials Today: Proceedings, vol. 32, no. 4, pp. 600-607, 2020. 
[35] A. Katz, "Properties of concrete made with recycled aggregate from partially hydrated old concrete," Cement and Concrete Research, vol. 33, no. 5, pp. 703-711, 2003.

[36] M. Safiuddin, M. A. Salam, and M. Z. Jumaat, "Effects of recycled concrete aggregate on the fresh properties of selfconsolidating concrete," Archives of Civil and Mechanical Engineering, vol. 11, no. 4, pp. 1023-1041, 2011.

[37] O. Boukendakdji, E.-H. Kadri, and S. Kenai, "Effects of granulated blast furnace slag and superplasticizer type on the fresh properties and compressive strength of self-compacting concrete," Cement and Concrete Composites, vol. 34, no. 4, pp. 583-590, 2012.

[38] A. Singh, P. K. Mohapatra, D. Kalyanasundaram, and S. Kumar, "Self-functionalized ultrastable water suspension of luminescent carbon quantum dots," Materials Chemistry and Physics, vol. 225, pp. 23-27, 2019.

[39] W. C. Tang, "Fresh properties of self-compacting concrete with coarse recycled aggregate," Advanced Materials Research, vol. 602-604, pp. 938-942, 2012.

[40] China Ministry of Construction, Chinese Standard JGJ552011, Common Concrete Mix Design Specification, China Ministry of Construction, Beijing, China, 2011.

[41] C. S. Poon and S. C. Kou, "Properties of self-compacting concrete prepared with coarse and fine recycled concrete aggregates," Cement and Concrete Composites, vol. 31, no. 9, pp. 622-627, 2009.

[42] Y. Kim, A. Hanif, M. Usman, and W. Park, "Influence of bonded mortar of recycled concrete aggregates on interfacial characteristics-porosity assessment based on pore segmentation from backscattered electron image analysis," Construction and Building Materials, vol. 212, pp. 149-163, 2019.

[43] Z. Ge, X. Liu, Q. Li et al., "Study on properties of selfcompacting concrete with recycled fine aggregate," Journal of Building Structures, vol. 49, no. S1, pp. 672-676, 2019, in Chinese.

[44] P. H. Zhu and Y. Lei, "Research on strength properties of concrete using aggregates from repeatedly recycling concrete waste," Applied Mechanics and Materials, vol. 665, pp. 147$150,2014$.

[45] X. Xiang, R. Zhao, F. Li, and P. Liao, "Experimental investigation of basic mechanical properties of self-compacting recycled aggregate concrete," Journal of Southwest Jiaotong University, vol. 54, no. 2, pp. 359-365, 2019, in Chinese.

[46] G. F. Belén, M. A. Fernando, G. L. Javier, and S. P. Sindy, "Effect of recycled coarse aggregate on damage of recycled concrete," Materials and Structures, vol. 44, no. 10, pp. 1759-1771, 2011.

[47] A. Hanif, Y. Kim, Z. Lu, and C. Park, "Early-age behavior of recycled aggregate concrete under steam curing regime," Journal of Cleaner Production, vol. 152, pp. 103-114, 2017.

[48] A. Katz, "Treatments for the improvement of recycled aggregate," Journal of Materials in Civil Engineering, vol. 16, no. 6, pp. 597-603, 2004.

[49] H. Beshr, A. A. Almusallam, and M. Maslehuddin, "Effect of coarse aggregate quality on the mechanical properties of high strength concrete," Construction and Building Materials, vol. 17, no. 2, pp. 97-103, 2003.

[50] A. F. Stock, D. J. Hannantt, and R. I. T. Williams, “The effect of aggregate concentration upon the strength and modulus of elasticity of concrete," Magazine of Concrete Research, vol. 31, no. 109, pp. 225-234, 1979.

[51] L. Wu, Z. Yan, and W. Jiang, "Study on aggregate in high strength and high performance concrete," Building Science Research of Sichuan, vol. 28, no. 3, pp. 55-58, 2002, in Chinese.
[52] Y. Li, Study on the Performance of Self-Compacting High Performance concrete, Central South University, Changsha, China, 2012, in Chinese.

[53] M. C. Limbachiya, T. Leelawat, and R. K. Dhir, "RCA concrete: a study of properties in the fresh state, strength development and durability," in Proceedings of International Symposium Sustain-able Construction: Use of Recycled Concrete Aggregate, pp. 227-237, University of Dundee, London, November 1998.

[54] J. Lavado, J. Bogas, J. de Brito, and A. Hawreen, "Fresh properties of recycled aggregate concrete," Construction and Building Materials, vol. 233, pp. 1-14, 2020.

[55] R. Kumar and B. Bhattacharjee, "Study on some factors affecting the results in the use of MIP method in concrete research," Cement and Concrete Research, vol. 33, no. 3, pp. 417-424, 2003.

[56] D. Winslow and D. Liu, "The pore structure of paste in concrete," Cement and Concrete Research, vol. 20, no. 2, pp. 227-235, 1990.

[57] H. W. Reinhardt and K. Gaber, "From pore size distribution to an equivalent pore size of cement mortar," Materials and Structures, vol. 23, no. 1, pp. 3-15, 1990.

[58] R. A. Cook and K. C. Hover, "Mercury porosimetry of cement-based materials and associated correction factors," Construction and Building Materials, vol. 7, no. 4, pp. 231-240, 1993.

[59] P. W. Barnhouse and W. V. Srubar, "Material characterization and hydraulic conductivity modeling of macroporous recycled-aggregate pervious concrete," Construction and Building Materials, vol. 110, pp. 89-97, 2016.

[60] J. M. V. Gómez-Soberón, "Porosity of recycled concrete with substitution of recycled concrete aggregate," Cement and Concrete Research, vol. 32, no. 8, pp. 1301-1311, 2002.

[61] L. K. Crouch, J. Pitt, and R. Hewitt, "Aggregate effects on pervious Portland cement concrete static modulus of elasticity," Journal of Materials in Civil Engineering, vol. 19, no. 7, pp. 561-568, 2007.

[62] S. Erdem, "X-ray computed tomography and fractal analysis for the evaluation of segregation resistance, strength response and accelerated corrosion behaviour of self-compacting lightweight concrete," Construction and Building Materials, vol. 61, pp. 10-17, 2014.

[63] J. Huo, X. Cao, X. Wang, Y. Ji, and H. Li, "Influence of natural pumice concrete pore structure on its compressive strength," Bulletin of the Chinese Ceramic Society, vol. 39, no. 3, pp. 84-89, 2020, in Chinese.

[64] J. Hu, Z. Qian, D. Wang, and M. Oeser, "Influence of aggregate particles on mastic and air-voids in asphalt concrete," Construction and Building Materials, vol. 93, pp. 1-9, 2015. 